\title{
MODELLING THE MICROFOUNDATIONS OF THE AUDIT SOCIETY: ORGANIZATIONS AND THE LOGIC OF THE AUDIT TRAIL
}

\author{
Michael Power \\ London School of Economics and Political Science, UK \\ m.k.power@1se.ac.uk
}

\section{ACKNOWLEDGEMENTS}

This is a single author paper only in name. I would especially like to thank editor Joep Cornelissen for his expert guidance, care and patience. In addition, I am indebted to his three anonymous reviewers. Many audiences have commented on previous manifestations of the ideas in this paper. In particular, I thank Peter Armstrong, Wai Fong Chua, David Cooper, Marie Laure Djelic, Wendy Espeland, Roger Friedland, Martin Giraudeau, Ann Langley, Michael Lounsbury, Donald MacKenzie, Afshin Mehrpouya, Andrea Mennicken, Anette Mikes, Peter Miller, Yuval Millo, Julia Morley, Danielle Morin, Jan Mouritsen, Tommaso Palermo, Brian Pentland, Sigrid Quack, Paolo Quattrone, John Roberts, Keith Robson, Kerstin Sahlin, Hendrick Vollmer, Stephen Walker, and Steve Woolgar. 


\begin{abstract}
We live in an "audit society" in which performance accounting and auditing requirements continue to expand, despite widespread criticism by academics and practitioners alike. Macro-institutional theories are good at explaining why organizations adopt practices whose efficacy is dubious by appealing to the power of their legitimizing and symbolic properties. Yet these theories are less able to explain how adoption happens and why practices of accounting and auditing persist and amplify, despite being objects of critique. This article addresses this puzzle by supplementing macroinstitutional explanations of the audit society with a microfoundational analysis grounded in a process model. The model theorises the humble notion of the audit trail as a process which not only produces auditable accounts but is also a logic which is formative of organizational actors' dispositions to reproduce those accounts. The analysis contributes to debates about organizational micro-processes and microfoundations by proposing that this logic of the audit trail is strongly performative of the conditions of its own reproduction and expansion. In explaining the persistence and amplification of the audit society, the model also shows how accounting and auditing are not inherently pathological and value-subverting but may be value-enhancing.
\end{abstract}

Key words: accounting, audit society, audit trail, disposition, facticity, institutional logic, meta-logic, performativity, Selznick, traceability 
Organizations are permeated by a wide variety of performance accounting and auditing practices (Bromley \& Powell, 2012). Indeed, it has been argued that we live in an "audit society" in which organizations are increasingly constituted to be auditable entities (Power, 1997). In addition to traditional financial accounts, organizations now provide reports on their performance regarding diversity, sustainability, quality, security, data quality, customer satisfaction, employee engagement and many other values besides. The scope of this performance accounting is continuously evolving and seems to have no limit. For example, in addition to reporting on research and teaching quality, UK universities have recently been required to report on the social and economic impact of their research outside of the academy.

The subverting effects of this explosion of accounting and auditing for the mission and values of organizations have been extensively documented, and are readily familiar to organization theorists: goal and attention displacement; elevation of process over ends; increased bureaucracy in the name of efficiency; declining trust in professional judgement; and crises of professional purpose (Bevan \& Hood, 2006; Cooper, 2001; Munro, 2004; Shore \&Wright, 2015; Strathern, 1997; 2000a; 2000b). Yet, despite these extensive critiques by both academics and practitioners, the seemingly dysfunctional and value-subverting practices of accounting and auditing persist and amplify.

Accounting scholars attribute the expanded organizational and societal significance of accounting and auditing practices to the central role they play in the realisation of "neoliberal" ideals of governance, control and accountability (Miller \& Rose, 1990; Miller \& Power, 2013). In a similar vein, macroinstitutional theories explain the adoption of ineffective and value-threatening practices in terms of their legitimising and symbolic power (Meyer \& Rowan, 1977). Thus, while accounting and auditing practices are manifestly adopted by organizations because they are compelled to so by regulation, they are also 
culturally valued embodiments of myths of rational organizational control, encompassing notions of transparency, accountability, and the power of the market (Meyer, 1986;

Dirsmith,1986; Christensen \& Cornelissen, 2015).

Yet, despite the generally compelling nature of these explanations for the adoption of accounting and auditing practices, they are less satisfactory, if not silent, on the question of how audit society effects unfold at the organization level. Indeed, if these changes are as negative in their impacts as critics suggest, why do they nevertheless amplify, self-perpetuate and sustain the rational myth status which drove adoption in the first place? How, for example, is the audit society progressively built up "from below" as organizations internalise and normalise requirements for audit and evaluation, and make themselves into "audit-ready" organizations? And how as part of this process do organizational actors become formed into "auditable" subjects who come to welcome and expand accounting and audit beyond the scope of formally mandated requirements? These questions cannot be answered at the level of macro-cultural myths and regulatory pressures alone. They demand supplementation by a microfoundational analysis of the audit society and its underlying processes (Thornton, Ocasio \& Lounsbury, 2012 chapter 7; Powell \& Rerup, 2017; Harmon, Haack \& Roulet, in press).

This article delivers this microfoundational analysis in the shape of a formative model of the accounting production process - the "audit trail". Despite an extensive body of scholarship on accounting and its organizational and societal effects, the mundane mechanism of the audit trail and its effects remains largely unstudied. In what follows it is modelled as a logic of organizing which operationalises and realises different performance values. Via repeated enactment, this logic of the audit trail is strongly performative (MacKenzie, 2006: 17) of the conditions of its persistence and amplification by forming the disposition of organizational actors to reproduce, refine and expand it in new settings. 
Indeed, the model shows how, despite being aware of the reductive and value-distorting impact of the performance accounts they must produce, organizational actors nevertheless come to make sense of them via the audit trail process as taken-for-granted representations of the facts of performance.

While the formation of subjectivities and the naturalisation of social facts are wellknown themes in sociological accounting (Miller \& Power, 2013), anthropology (Douglas, 1986) and general sociology (Berger \& Luckmann, 1966), the contribution of the proposed model of the audit trail is to integrate these constructs in the theorization of a formative process, thereby grounding the microfoundations of the audit society. The model explains not only how audit trails and the accounts they produce are adopted and embed themselves in organizational routines despite critiques of their lack of efficacy, but also why they expand and amplify within and across different specific performance accounts and organizations.

A further unexpected contribution of modelling the microfoundations of the audit society is a more general reading of means-end decoupling (Bromley \& Powell, 2012; Wijen, 2014; 2015; Dick, 2015) in which values are not just "precarious" (Selznick, 1957: 119) and at risk from proceduralization, as the many critics of the audit society argue. Rather, via the logic of the audit trail, values can also acquire organizational visibility, operability, and a facticity that they would otherwise lack. In short, implicit in the model is a general performative theory of how values can acquire organizational facticity via accounting. This insight requires us to recast the well-documented pathologies of the audit society in terms of trade-offs between the risks and benefits of accounting for values.

The remainder of this article is structured as follows. The next section synthesises insights from performative studies of accounting and auditing and themes in institutional theory. This synthesis converges on the problem of audit society microfoundations and leads 
to the explication of the audit trail as a widely diffused logic. This logic is then explicitly modelled as a strongly performative process in which the disposition to reproduce that logic and accounting facticity are co-formed over time. The argument is distilled into a core proposition, the contingent dynamics of which are then considered in more depth; focusing on the organizational conditions under which the performativity of audit trails might be stronger or weaker. Finally, the article engages with Selznick's thought to explore how the microfoundations of the audit society reveal a process which is not inherently pathological before developing some of the wider implications and limitations of the theory.

\section{ACCOUNTING PERFORMATIVITY, INSTITUTIONALISM AND AUDIT SOCIETY}

Performative theorizations of accounting pre-date debates about performativity in management and organization studies (Burchell, Clubb, Hopwood, Hughes \& Nahapiet. 1980: 17; Hines, 1988; Miller \& Power, 2013; Gond, Cabantous, Harding \& Learmonth, 2016). In the 1980s, the recognition that accounting constitutes the organizational context of its own operations established an agenda in accounting research which transcended the predominant analysis of behavioural reactions to accounting information (Miller \& Power, 2013). It rapidly became axiomatic that accounting does not just "represent" the pre-given facts of organizational performance, but is agentic in its own right. It constructs the reality or "facticity" of performance that organizational actors come to take for granted (Chapman, Cooper \& Miller, 2009; Dent, 1991; Mazmanian \& Beckman, 2018).

It is also argued that the accounting process performs "governable persons" in the sense of organizational agents who orient themselves to the requirements of accounting and who internalize the categories used to describe them (Miller \& O'Leary, 1987; Miller, 1992). 
Accounting is thereby understood to be a calculative technology (Foucault, 1977; Miller, 1992; Townley, 1993) whose power is not hierarchical and manifestly coercive, but progressively constitutes and "makes up" subjects and their identities as performanceaccountable actors (Hacking, 2002).

Furthermore, accounting is deeply implicated in the "economization" of organizations i.e., in performing them as rational economic entities (Mennicken \& Espeland, in press). For example, anticipating explicit formulations of performativity theory by many years, Hopwood argued that the cost of patient care was a "conceptual idea promoted by health economists but, without accounting, it could not become operational as an "organizational fact” (1992:141). Classical articulations of performativity theory (Callon, 1998; MacKenzie, Muniesa $\&$ Siu, 2007) also recognise how calculative practices like accounting operationalise economic models and theories, thus enabling economics to perform and constitute markets. However, accounting is not simply an enabling instrument though which economic theory is performative. Fundamental notions of "income" and "cost" have evolved from theoretical and metaphorical exchanges between accounting practices and economic theories (Klamer \& McCloskey, 1992), and accounting is itself a theoretically-infused practice. It is not a scientific theory with predictive ambitions, although there has been an ambition to predict financial failure on the basis of accounting numbers (Kurunmäki \& Miller, 2013). Rather, accounting is able to be "practical" precisely because it is also theoretical in the sense of abstracting, reducing and commensurating complex economic and other phenomena into organizing typologies, like the balance sheet (Espeland \& Stevens, 1988; Astley \& Zammuto, 1992: 455; Strang \& Meyer, 1993).

Accounting and economics have a broad cultural fit and mutually authorising relationship with one another (Hopwood, 1992; Vollmer, Mennicken \& Preda, 2009). Moreover, this conceptual affinity with financial forms of accounting explains why economic 
theories may be more performatively successful than others (Marti \& Gond, 2018), even if they are unsuccessful in terms of societally-valued outcomes (Zuckerman, 2010). At its strongest, the performativity of accounting is analogous to that of a self-fulfilling theory (Barnes, 1983; MacKenzie, 2006) which is “ontologically performative” (Butler, 2010: 147; 1999), i.e., its repeated enactment or "citation" brings about and sustains the organizational conditions for the continued production of its own kind of "accounting truth" about performance (Hines, 1988; Miller \& Power, 2013). In short, accounting is performative of its own "facticity", in the sense that organizational actors accumulate a disposition to act "as if" its economic representations are "about" an independently existing world.

However, this accounting-produced truth is also bounded by a "logic of auditability" (Power, 1996). Accounting and auditing practices perform organizations as economic entities, but also as auditable ones. Furthermore, practices of auditing and evaluation do not simply check and evaluate the independently constituted performance of organizations and individuals. Instead, organizations and their members are changed, or change themselves, in order to be ready for audit, to be "made auditable". Indeed, it will be argued that this process of organizational structuring, by which organizations create control systems and reporting structures in order to be amenable to observation, inspection, and evaluation, is where the generative engine of the "audit society" is to be found.

\section{The Audit Society}

The concept of the "audit society" (Power, 1997) refers imprecisely to the expansion of new forms of accounting and performance measurement in public sector management in the United Kingdom and elsewhere. The immediate cause of this expansion is attributed to a bundle of "animating myths", namely a neoliberal political consensus in the early 1980s and its heightened emphasis on values of transparency, efficiency, responsibility, auditability and 
accountability, which characterised the reform vectors of a so-called "new public management" ((Bromley \& Powell, 2012: 498; Hood, 1995). Accounting and audit grew in cultural and organizational significance as the rational means by which this bundle of myths could be operationalised (Meyer, 1986; Miller \& Rose, 1990; Power, 1997: 96; Bromley \& Sharkey, 2017). This in turn created opportunities for powerful actors, like professional service firms, to codify and expand the abstract building blocks of auditing beyond their context of origin to form new advisory services (Meyer \& Rowan, 1977: 347; Suddaby, Cooper \& Greenwood, 2007).

There is no shortage of criticism of audit society effects, such as goal-displacement and the "gaming" of new performance accounts and related metrics (Hood, 1995; Bevan \& Hood, 2006). It is also argued that "intrinsic" motivation has been displaced or damaged by the introduction of "extrinsic" incentives systems in which the "language of indicators takes over the language of service" (Strathern, 2000b, 314). These critiques find theoretical support in behavioural studies which show how excessive control may "crowd out" good motives to the extent of inducing organizational actors to act self-interestedly, and even deviantly (Frey \& Jegen, 2001; Falk \& Kosfeld, 2006). Selznick’s (1957) diagnosis of valuesubversion, by which technical routines acquire excessive moral authority in organizations, anticipates these critiques by several decades: "The tendency to emphasize methods rather than goals is an important source of disorientation in all organizations" (Selznick, 1957: 12). However, few critiques of audit society effects have drawn on Selznick's insights to explain and theorize its persistence and self-reproducing capacity (Power, 1997:144).

Audit society processes are resilient to these many criticisms because they draw upon the bundle of myths noted above, not least that of transparency (Christensen \& Cornelissen, 2015). Transparency is known to be paradoxical (Tsoukas, 1997; Roberts, 2018) and many of the audit society practices invoked in its name in fact lead to opacity and specialist control 
(Strathern, 2000b). However, as Christensen and Cornelissen (2015) argue, the myth of transparency remains immune to these specific manifestations and their problems. It is "somehow sheltered from critique" and its lack of specificity is part of its mythical and moral power. Thus, even if organizational actors want to resist the audit society and its valuesubverting, reductive accounts of performance, they confront the cultural power of this myth of transparency as it is manifest in specific accounting representations.

Yet, despite the influence of this audit society thesis as stated, it lacks an explicit model of its generative microprocesses. The aforementioned studies of the performativity of accounting and auditability refer to these processes but are themselves insufficiently precise about their dynamics. Furthermore, macro-level explanations of the audit society in general "rational myth" terms, such as transparency and neoliberalism, are inevitably limited in their explanatory power. They may explain why the adoption of accounting and auditing practices happens but not how it happens and why such practices seem to have "practice shifting performativity" (Marti \& Gond, 2018). For this we need to develop a microfoundational model based on a deeper engagement with institutional theory.

\section{Towards the Microfoundations of the Audit Society}

The artificial duality between old and new institutionalisation (DiMaggio \& Powell, 1991: 13) has given way to a consensus that macroinstitutional explanations of change can and must be supplemented by arguments at the micro-level, where practices are enacted by organizational actors with varying degrees of mindfulness (Pentland, 1993; Selznick, 1996; Greenwood \& Hinings, 1996; Hirsch \& Lounsbury, 1997; Thornton et al., 2012; Barney \& Felin, 2013). Specifically, in reaction to the perceived abstractionism and processinsensitivity of macro-institutional approaches, there has been a turn towards the role of agency and discourse in creating, maintaining, resisting or even destroying institutions 
(Phillips, Lawrence \& Hardy, 2004; Lawrence, Suddaby \& Leca, 2009; Thornton, et al., 2012). Powell and Rerup argue further that micro-level explanations provide the necessary "depth and texture to accounts of macro-level events and relationships" (2017:312). They point to practice theory, ethnomethodology, and routines theory as resources and reminders that habitual activity involves sustained mindful reflection and effort (Felin, Foss, Heimeriks \& Madsen, 2012). In essence, a more process-sensitive theory of reality is needed in place of the macro-neoinstitutionalist emphasis on "cloned" organizations (Abbott, 1995: 879).

Although approaches to, and concepts of, microfoundations are varied (Felin, Foss \& Ployhart, 2015; Barney \& Felin, 2013) they commonly shift the level of analysis from a Durkheimian bias to macro-stability towards an understanding of micro-level practices and variation (Lounsbury, 2008). Furthermore, they emphasise institutional complexity and pluralism in which human agents navigate, and account for, competing values and logics (Thornton, Jones \& Kury, 2005; Thornton et al., 2012; Greenwood et al., 2011). In short, it has become paradigmatic for institutional theory that organizational agents are not slaves to specific macro-cultural myths of rational practice and governance but actively generate, maintain and resist such myths as they operate in value-plural landscapes in different fields (Kraatz \& Block, 2008).

This wave of microfoundationalist reactions to the macro-cognitive "cloning" institutionalism of scripts and habit (DiMaggio \& Powell, 1991) has also generated a revival of interest in values, and particularly in the work of Phillip Selznick and his focus on processes of "value change and subversion" (Kraatz \& Block, 2008; Kraatz et al., 2010: 1522; Kraatz \& Flores, 2015). Indeed, as noted above, Selznick identifies and anticipates the symptoms of the audit society at the organizational level where "achievement or survival is confounded with organizational success" (1957:27). He observes that organizations can fail dismally (in their core mission) while growing larger and more secure (financially). 
Specifically, when organizations make seemingly innocuous operational changes, such as new performance accounting requirements, they necessarily place values at risk of crowdingout by process, unless there is corresponding vigilance and intervention by organizational elites (Besharov \& Khurana, 2015). Three broad value-subverting outcomes of these operational changes characterise the audit society (cf. Kraatz et al., 2010). First, as accounting and accountants become more powerful, "internal elites", such as professional service providers, lose their autonomy and licence to define the values and performance of the organization. Second, and relatedly, "power shifts to the operative system" in the form of the performance accounting infrastructure and its logic. And third, "market values penetrate the organization" via the performative power of accounting as discussed above.

In these circumstances of value-subversion, where we would normally expect organizational resistance, such as decoupling, the very opposite is observed (Espeland \& Sauder, 2007; Sauder \& Espeland, 2009; Kraatz et al., 2010). Operational practices, like accounting and auditing, are introduced to represent performance and to change decisionmaking and behaviour on the basis of those representations. Yet they also become institutionalized practices which are "prized for their own sake" (Selznick, 1957: 17) and underwrite the professional autonomy of their proponents. Bromley and Powell (2012: 498) theorize this organizational outcome as "means-ends decoupling", defined as the symbolic implementation of means like accounting which follow their own logic. They argue that this kind of decoupling is on the rise and is increasingly evident in situations where there are uncertain relations between means, like accounting, and imprecise ends, such as diversity, respect or environmental sustainability. Like scholars of bureaucracy from Weber onwards, including Selznick and his followers, Bromley and Powell suggest that value subversion is hard to prevent via classical "policy-practice" decoupling (Meyer \& Rowan, 1977; Zajac \& 
Westphal, 2004) because technical means develop their own rationales. To use older sociological language - procedural rationality eclipses substantive rationality.

The audit society is a form of means-end decoupling on a macro-scale and is characterised by an "increasing emphasis on monitoring and tracking organizational activities." (Bromley \& Powell, 2012: 484). This is not only the expansion of traditional financial accounting and auditing but, as organizations are required to process expanded claims on performance embodying a wider array of societal values, it is also an expansion of the accounting and monitoring for many non-economic values, such as social impact. This world of multiple accountabilities and performance accounts is one in which data collection and measurement rapidly become ends in themselves, exacerbated by the demands of audit and regulation (Bromley \& Powell, 2012: 501), and where new forms of accounting and metrics are constantly being sought and refined to provide assurance to potentially critical audiences.

Yet, while the categories of coupling and decoupling have played a major role in orienting organizational studies (Boxenbaum \& Jonsson, 2017), we need to open the "black box" (Powell \& Rerup, 2017) of these concepts to reveal more of the audit society microprocesses that give rise to, and seem to stabilise as, means-end decoupling (Dick, 2015). Just as macroinstitutional theories emphasize how organizations are strongly influenced by cultural forces, so micro-level analysis can reveal how organizational actors "pull" down and adapt (Ansari, Fiss \& Zajac, 2010) institutionalized scripts of good accounting and auditing as standard operating procedures (Pentland, 1993; Thornton et al., 2012: 85). And while "means-end decoupling" is a helpful sensitising concept for understanding how new accounting and auditing practices can generate their own autonomous logic and subvert values in Selznick's sense, it is insufficiently granular for modelling the process by which organizational actors are "imprinted” (Barney \& Felin, 2013; Marquis \& Tilcsik, 2013; 
Cardinale, 2018; Harmon, et al., in press) with dispositions to reproduce these valuesubverting practices. Developing this micro-level theory in the form of a model of how the audit society sustains itself is the task of the remainder of this article.

In summary, the audit society can be theorised as systemic means-ends decoupling arising from macro-institutional adoption of auditing and accounting practices. Yet how adoption happens and why it reproduces itself and makes "organizations auditable" requires a more fine-grained, micro-processual analysis. We find this analysis and a more compelling theory of the persistence of audit society effects, despite widespread critique, at the level of the performative dynamics of the "audit trail". In fact, it will be argued that the audit society is built and stabilised from below via the repeated enactment of the audit trail process. And in theorising how the audit society sustains itself at this microfoundational level, we also find a process which explains why the amplification and elaboration of seemingly valuesubverting practices occur. Before we get to this, we need to understand the construct of the audit trail more fully.

\title{
THE AUDIT TRAIL AS "META-LOGIC"
}

\begin{abstract}
Strang \& Meyer, 1993) of audit trails are plentiful. For example, an audit trail has been defined online by a professional training organization as a:
\end{abstract}

"the documented flow of a transaction. It is used to investigate how a source document was translated into an account entry, and from there was inserted into the financial statements of an entity. The audit trail can be used in reverse, to track backwards from a financial statement line item to the originating source document. A well-run accounting system should have a clear audit trail for all transactions. An audit trail is used by both external and internal auditors to trace transactions through an accounting system, as well as by the accounting staff to track down errors and the causes of variances in the financial statements." (Emphases added) (Accounting Tools, 2018) 
Within this rich definition, the audit trail is multifaceted (Kraatz, Ventresca \& Deng, 2010: 1525) and variable in its ontology. First, it is material and textual (Phillips et al., 2004) consisting of documents, records and traces which are the created evidentiary residues of transactions. Second, it is ideational. An audit trail operationalizes the cultural ideal of transparency as traceability (Power, in press). Third, the audit trail is processual. The definition references both a process for producing accounts of performance by the aggregation of primary data, the progressive abstraction and commensuration of the chronological stream of organizational transactions, and also a process by which these accounts can be checked by auditors. The remainder of this article focuses primarily on this processual ontology of the audit trail and expands it to encompass the formation of actor dispositions and the production of accounting facticity.

Empirically, audit trails are not restricted to financial bookkeeping and are evident in many different settings where there are institutional pressures to account for different aspects of organizational performance (Phillips et al., 2004: 642: Bromley \& Powell, 2012; Marquis, Toffel \& Zhou, 2016). For example, audit trails are central to computer security practice and enable the detection of unauthorised usage, fraudulent transactions, and other deviant actions which leave traces in the system (e.g. Merconi, 2003). And they are increasingly prominent in settings where the origins, quality and sustainability of foodstuffs have become important to consumers, e.g., GM crops (Lezaun, 2006) or palm oil (Rival, Montet \& Pioch, 2016). In the seafood industry, the traceability enabled by audit trails is valued for its own sake and inter-operative digital technologies, such as blockchain, are supporting the creation of precise point of harvest data (WWF, 2015; Lewis \& Boyle, 2017). Thus, audit trails can be transorganizational and trans-national when the unit of performance accounting is an entire supply chain. 
These and other empirical instances of audit trails can be understood as specific tokens of an underlying type or process logic for the production of organizational performance accounts. This logic consists of two sequential sub-processes as follows:

\section{The Production of "Primary Traces" of Performance (A).}

The "atomic facts" of performance are created by organizational actors utilizing a variety of instruments and artefacts, such as account daybooks, questionnaires and checklists. The traces in these artefacts, whether documentary or digital in nature, are a distinctive kind of organizational text which is coherent and amenable to structuring and aggregation into organizational-level performance accounts. The logic of the audit trail therefore demands the production of primary traces which are reductive (reduce complexity) and systematic (standardised) representations of actions in simplified inscriptions which can be aggregated. They are often but not always numeric. Such primary traces constitute and define the auditability of performance.

\section{The production of organizational performance accounts (B).}

In this second sub-process, the primary traces of performance are systematically aggregated into public and private organizational-level accounts. This aggregation process can also be extended as accounts are subject to further compression into metrics, and then formally ranked to enable comparisons of performance across organizations in different fields. Audit trails are therefore deeply implicated in the production of rankings and ratings.

These two components constitute the sequential logic of the audit trail as a process of accounts production from primary performance data. Each of these sub-process types are likely to contain many more specific routines with their own protocols, artefacts and enactments (Feldman \& Pentland, 2003). Sub-process B and the specific output tokens of the audit trail process in the form of performance accounts of different kinds - especially 
financial reporting, environmental disclosures and rankings - have received considerable attention from accounting and organization scholars. In contrast, the micro-level of subprocess A is relatively unexplored, despite being the engine of sub-process B.

Understood as a type, the process logic of the audit trail seems to lack any specific content or performance value, other than the imperative to produce performance accounts in accordance with the requirements of making performance traceable to primary performance data. Specific first order performance values such as "profit", "fairness", "diversity", "sustainability", and "impact" determine the contingent and potentially varying empirical tokens of the logic of the audit trail. How and to what this logic is applied seems therefore open and uncertain, but also unbounded. On this view, the logic of audit trail can institutionalise performance values, but is neutral about them.

Yet, the value-neutrality of procedural logics is questionable (Quattrone, 2015; Friedland, 2017). As a type, the logic of the audit trail is better conceptualised as "metalogic" which is substantive and formative in its own right. Thus, if first order values are to feature in formal performance accounts, they are necessarily subject to, and processed by, the meta-logic of the audit trail. This logic appears to be merely procedural but, as the bearer of the bundle of organizing myths referred to earlier, it is a second order-value which organizes first order values into accounts. It is not sectorally or value-specific, hence its meta-logical status, and as a logic or type it cannot exist apart from the tokens which embody it (Friedland, 2017). Yet it is more than merely formal; it cuts across field and sector-specific logics and their multiple dimensions and tensions (Thornton et al., 2012).

To summarise: while the concept of the audit trail is closely associated with financial accounting, it has an abstract process logic $(\mathrm{A} \rightarrow \mathrm{B}$ above $)$ which is not confined to its specific enactment in the bookkeeping paradigm. As an abstract type, the audit trail is a 
globally diffused (Strang \& Meyer, 1993) "meta-logic" for organizing the production of performance accounts in general. The dynamics of this logic constitute the microfoundations of the audit society, understood as a continuously unfolding and repeating organizational process of accounts production. As we now argue, this logic has "explosive organizing potential" (Meyer \& Rowan, 1977; Power, 1997: 96) and is strongly performative of the conditions of its own perpetuation.

\section{A PROCESS MODEL OF AUDIT TRAILS: FACTICITY AND DISPOSITION FORMATION}

It has been argued above that prior studies of the formative and performative dynamics of accounting require more elaboration of micro-processes, not least to understand the paradox that efforts to resist performance accounts, such as rankings, end up extending their power. Indeed, sustained attention towards "primary traces" of performance, such as student placement data, seems to promote coupling rather than decoupling (Sauder \& Espeland, 2009: 64). Exactly as Durkheim (1982) claimed for social facts in general, rankings in particular and accounting in general assert themselves, and are attractive to organizational leaders, even in the face of efforts to resist them. On the one hand, accounting objectivity, its taken-for-grantedness or "facticity" is produced as performance accounts receive more organizational attention and are normalized. Organizational actors are drawn to externalisations of their performance in accounting numbers, experience their authority as social facts and the possibilities of comparability they bring, and welcome their complexity reducing properties (Esposito \& Stark, in press). Accounts may even be a source of pride for critics and supporters (Sauder \& Espeland, 2009). 
On the other hand, reflexive organizational actors are also critical of the reductive, partial and "unrealistic" nature of rankings as representations of performance. Although they perceive rankings as undermining core values, they also have little choice but to produce such representations and pay increasing attention to them. So, even as they criticise rankings they are entangled in their reproduction. In what follows, we integrate these two conflicted processes - allure and resistance, "pull" and "push" - in a micro-processual and formative model of the audit trail. Before articulating this model explicitly, it is necessary to clarify two of its key conceptual units - "facticity" and "disposition".

\section{The Facticity of Performance.}

The notion of "facticity" is often used interchangeably with that of "objectivity". Yet it has distinctive origins in the philosophy of German idealism and is associated with the work of thinkers such as Husserl, Heidegger and Merleau-Ponty. The concept is part of the vocabulary of phenomenological psychology and refers to the way facts appear, and are experienced, as facts. Facticity is the quality of taken-for-grantedness or "givenness" of experience (Friedland, 2017). It is the way things like accounting statements are taken as referring to, and producing facts about, the world. The concept also has currency in general sociology, not least in the work of Garfinkel who was influenced by phenomenology: “.....every feature of an activity’s sense, facticity, objectivity, accountability, communality is to be treated as a contingent accomplishment of socially organized common practices" (Garfinkel, 1967: 33, emphasis added). On this view, facticity is an institutional rather than a transcendental accomplishment (Douglas, 1986).

Accounting facticity has little to do with truth or accurate representation. In an age of "fake news" (Allcott \& Gentzkow, 2017), it is not surprising that "false" numbers (Lampland, 2010), "bad" measures (Dambrin \& Robson, 2006) and "selective disclosures" (Marquis et 
al., 2010) can acquire organizational and social facticity. In effect, accounting numbers come to be seen, and made sense of, by actors as referring to an organizational reality of performance. More generally, it is the job of phenomenological and sociological analysis to recover these collective processes by which facticity is formed (Berger \& Luckmann, 1966: 78). Accounting, despite its numerous scandals and failures, seems to possess a facticity so authoritative and so securely grounded in modernity "that we have trouble imagining other forms of coordination and discipline or other means of creating transparency and accountability" (Espeland \& Sauder, 2007: 5).

Facticity as an acquired taken-for-grantedness is not only a property of forms of quantification like accounting. It is also an effect of documentary processes in general. (Smith, 1984: 66). We know that organizations are saturated in documents and digital records and texts: files, diaries, memos, timesheets, questionnaires, checklists, log books as well as formal accounting records (e.g. Riles, 2006; Phillips et al., 2004). These organizational documents or artefacts do not simply mirror organizational events. As elements of routine practices they perform "organizational facts" (Garfinkel, 1967; Smith, 1984; Cooren, 2004; D’Adderio, 2008; Hull, 2012; Kaghan \& Lounsbury, 2006). This performative power has little to do with whether documents describe any specific work process faithfully or accurately. Rather, they produce facticity by subsuming that process within the formal, reductive schema of the document that represents it (Garfinkel, 1967; Smith, 1984). Extending this reasoning, what is recorded in an audit trail primary trace is never simply "what happened” (Van Maanen \& Pentland, 1994; Hull, 2012). It is a redescription of an action according to an institutional purpose - accounting for performance in a specific way - which is more or less widely accepted by organizational actors. Primary traces are therefore the paradoxical engines of performance facticity: they are known to be 
simple and reductive but they generate a reality which is experienced by, makes sense for, and is desired by, organizational actors.

In what follows, the concept of facticity is preferred to that of objectivity, which is often contested and crudely counterpoised to "subjectivity." It is also more processual and experiential in connotation, having affinities with Berger and Luckman's (1966:49) notion of "objectivation" as something produced by social actors. In the context of performance accounting, facticity results from the repeated, collective externalization of performance representations. Organizational actors experience and increasingly make sense of these performance accounts as not simply conventional in nature, but as being about, and referring to, the world (Douglas, 1986). They experience the "pull" or "compelling and coercive power" (Durkheim, 1982: 51) of performance accounts as "social facts". And this accounting facticity strengthens with the accretion of accounting infrastructure in the form of audit trail routines for accounts production.

\section{The Concept of Disposition.}

The concepts of disposition and habit are closely related (Camic, 1986:1044). For Dewey habit is equated with a disposition to particular ways of acting which are acquired through past experience (Dewey, 1922; Turner \& Cacciatori, 2016:78). He understands habit not just as a mechanical, automatic response to triggers, but also as a positive force for learning and agency (Cohen, 2007). This richer concept of habit and agency has influenced the understanding of organizational routines as generative accomplishments by mindful actors (Feldman \& Pentland, 2003). Indeed, a more varied typology of habit recognises that while it may be an acquired tendency or inclination in the face of repeated experiences, automaticity is but one point on a spectrum of possibilities (Turner \& Cacciatori, 2016). 
Bourdieu transforms the notion of habit from its origins in the psychology of the individual into the sociology of habitus. Habitus is understood as the sum of acquired abilities or dispositions formed from the entanglement of individual embodied life history and structural position in fields (Butler, 1999). Thus, what Bourdieu calls the "aesthetic disposition" is a generalised capacity traceable to specific forms of the division of labour in society (Bourdieu, 2010: 47). On this view, dispositions are pre-reflective but also flexible and purposive in the sense of a skilled performance by an expert player of a game (Crossley, 2013: 139). Cardinale (2018) builds on Bourdieu's approach to argue that social structure is neither inherently "enabling” or "constraining" (Adler \& Borys, 1996) but "imprints" orientations or dispositions which may vary in their reflexivity or automaticity, as argued by theorists of habit.

In what follows, Bourdieu's grounding of the category of disposition in the formative nature of wider social structures is "bracketed" both for exegetical reasons and also to avoid burdening a micro-level analysis of audit trails with the structure-agent debate (Harmon et al., in press). The model focuses instead on disposition-formation arising from repeated microencounters with, and enactments of, the "game" of performance accounting via the production of primary traces. By adopting this restricted focus on organizational sites of disposition-formation, the model leans more towards Foucault (Townley, 1993) than Bourdieu. Both Bourdieu and Foucault share a critique of the autonomous self but differ importantly in how they conceptualize the processes by which subjects are formed (Callewaert, 2006; Cronin, 1996). Where Bourdieu locates this formative process firmly in the class structure and social position, Foucault locates it at the micro-level of encounters between individuals and infrastructures of control and their discourses - what he calls the dispositif or "apparatus". For Foucault, subjects and their dispositions are formed from 
immersion in material devices of control and their textual "systems of intense registration" (Foucault, 1977:188), such as primary trace production for audit trails.

\section{A Process Model of the Audit Trail}

Having refined the concepts of facticity and disposition, drawing on very different theoretical traditions and reference points for each, we now integrate them within an extended model of the audit trail process which captures the tension between allure and resistance noted earlier. The architecture of this model adopts Berger and Luckmann's (1966: 78) wellknown typology of institutionalisation which theorizes three fundamental dialectical and formative processes: "externalization", “objectivation" and "internalization". In the proposed model, these three process types are extended by analogical reasoning (Swedberg, 2014; Ketokivi, Mantere \& Cornelissen, 2017) respectively to: the production of primary traces; the emergence of performance facticity from the production of accounts; the formation of dispositions to reproduce audit trails. Furthermore, the dialectical dynamics identified by Berger and Luckmann are further specified in terms of MacKenzie's well-known typology of contingently unfolding performativity (MacKenzie, 2006: 17; Marti \& Gond, 2018;

D'Adderio, 2008). This enables us to begin by theorizing three discrete logical stages of a formative process as a static sequential analysis, before elaborating the dynamics of transition between these stages. In effect, we are building a performative model of an institutionalizing process.

Stage 1. This stage, which begins with adoption, is characterised by generic or weak performativity in MacKenzie's sense. As macroinstitutional theories suggest, actors adopt new audit trail requirements because of the exogenous compulsion of a bundle of myths as sources of legitimacy, but they also do so to avoid regulatory sanction (Thornton et al., 2012: 87). In this first stage of audit trail production, new organizational accounts of performance 
have limited initial facticity for organizational actors, especially where primary trace production is ad hoc and non-routine. The disposition to reproduce audit trails in the absence of regulatory and institutional pressure is weak. Actors adopt and comply because they must for cultural and regulatory reasons, but are aware of the conventional nature of the accounts produced, and are openly critical of performance reductionism and value subversion. In this stage of weak performativity, they are also likely to engage in strategic compliance, decoupling and even deviant actions in relation to performance accounting (Oliver, 1991:152).

Stage 2. The second stage is effective or medium performativity. It is characterised by the increased repetition and routinization of primary trace production within infrastructures for accounts production. As a consequence of this routinization, the organizational facticity of accounted-for performance increases for organizational actors because they have little choice but to pay more attention to the audit trail process in their work. Yet, even though these actors are immersed in performance accounting and make sense of, and operationalise, their performance as represented in accounting systems, they still retain a reflexive capacity to be critical and strategic about the adoption of performance accounts (Turner \& Cacciatori, 2016). However, in contrast to stage 1 , this critique is more reformist than rejectionist. Organizational actors want to make performance accounts "less bad" or improve them, rather than dismiss them outright.

Stage 3. The third stage of performativity of the audit trail process is strong or “Barnesian” performativity (Barnes, 1983; MacKenzie, 2006; Marti \& Gond, 2018). At this stage, the facticity of performance accounts exerts a strong influence over actors whose disposition to produce audit trails becomes less reflexive about value subversion, less dependent on macroinstitutional factors or regulatory push, and more automatic in nature. The formation of such a disposition means that organizational agents are constituted as 
carriers of the abstract logic or type of the audit trail regardless of its efficacy. They are now agents of its replication, amplification and expansion into new performance reporting settings (Turner \& Cacciatori, 2016: 78).

\section{Insert Table 1 about here}

Table 1 summarises and depicts the three stages of audit trail performativity as a temporal sequence culminating in strong form performativity. A more dynamic reading of this sequence is needed to understand how audit trails transition between the stages and become strongly performative and amplificatory. In essence, strong performativity emerges from a mechanism of positive cumulative feedback from exposure to the audit trail process. The audit trail is not itself a self-fulfilling theory but has analogous looping effects as facticity, disposition and primary trace production positively reinforce each other (Barnes, 1983). It is this strengthening of the performativity of audit trails which explains both how organizations adopt accounting and auditing practices which may be ineffective and valuesubverting, and also why they expand in ways that cannot be explained by structural or regulatory pressures in organizational environments, pressures which only explain adoption. The mechanism of this transition between stages is theorized below in terms of a dispositional conflict between two forces, which we simplify with the metaphors of "push" and "pull".

Push. This is understood as critical resistance by organizational agents to new performance requirements, and is well documented in studies of audit society pathology, such as the reaction of doctors to new performance appraisal systems (McGivern \& Ferlie, 2007), as well as more generally (Oliver, 1991). Organizational agents make sense of primary 
traces as simplistic and reductive. They are regarded as in conflict with existing values, with more expansive and less reductive ways of making sense of work practices, and with their own identities in performing this work (Thornton et al., 2012: chapter 7). Push is both emotional and cognitive (Cohen, 2007; Voronov \& Weber, 2016; Lok, Creed, DeJordy \& Voronov, 2017) and results from anxiety in the face of new modes of performance evaluation (Espeland \& Sauder, 2016). Push should not be equated with active or organized resistance, for which many other enabling conditions are needed. It is essentially dispositional in nature; push is resistance to performance value internalization.

Pull. This points to a different dispositional vector, namely the attraction of organizational actors to the externalization of their performance in primary traces and the facticity of the accounts which they produce. This idea takes its theoretical lead from Durkheim's notion of the compulsion of social facts. Like push it can be grounded psychologically (Cohen 2012; Winter 2013) and psychoanalytically (Cooper, 2001; Voronov $\&$ Weber, 2016) as a desire by organizational actors to externalise, and make sense of themselves and their performance in primary traces. As noted above in the discussion of facticity, pull also exists when features of performance accounting lose their conventional status and come to be understood and communicated by organizational actors as representations of the way things are. This recursive interaction between an emotional desire for identity, validation and complexity reduction in externalized representations of performance, and the increased organizational facticity of such performance presentations, drives the formative process from stage 1 to stage 3 . Academic readers might reflect on the affirmation and gratification provided by citations of their work despite their misgivings. Citations have become "facts" about researcher performance despite widespread critique of their crudity as measures. 
The model dynamics are therefore constructed from a simple psychological mechanism of conflict-resolution between push and pull, between a desire to resist and push away from performance reductivism, and the Durkheimian compulsion or pull of performance facticity. This push and pull can be modelled as a recursive sensemaking process in which the material practice of primary trace and account creation (externalization), progressively generates collective meaning in the form of facticity (objectivation) which in turn generates a desire or disposition to account (internalisation). Once set in motion, this dynamic of primary trace production, facticity emergence and disposition formation becomes endogenous (Dionysiou \& Tsoukas, 2013). Organizational actors welcome and desire the production of audit trails and performance accounts, regardless of their efficacy or valuesubversion.

Returning to the three stylised stages of performativity in table 1, we can express the logic of this recursive process as follows: in stage 1 primary traces are produced by organizational actors but push is strong and the pull of accounting representations is weak. The production of primary traces is not a priority for organizational actors and bears little relation to existing work and value dispositions which remain intact. As the process of primary trail production is repeated and embedded in organizational routines, stage 2 is reached in which primary traces necessarily require increasing time and attention from organizational actors, making them less critical about their limitations than stage 1. As infrastructure for the production of primary traces accretes, primary traces also acquire facticity and exert more pull over actors. In the face of this, continued critique is psychically and economically costly and continued employment may be at risk. Resistance mutates into a more strategic attitude to the production of primary traces, not least by editing, adapting and improving them. In stage 2 the initial dispositional conflict is being resolved as pull strengthens and push weakens. 
By stage 3, organizational actors have experienced extensive exposure to audit trail production. Both primary trace and performance accounts are products of mature infrastructures and have acquired strong facticity for organizational actors. Performance is fully externalized and objectified. Performance accounts are not simply compositional aggregates of primary traces; facticity is an emergent and dynamic property (Barney \& Felin, 2013) of their production process. The outcome is that organizational performance has become auditable in a way that comes to seem entirely natural and self-evident to organizational actors. Repetition of the audit trail process creates ever "deeper ruts in the road" for organizational actors (Pentland, Haerem \& Hillison, 2011) and the disposition to reproduce and expand them is strong.

Under the strong form performativity of audit trails, primary documentary traces are no longer objects of reflexive critique for their reductionism and conventionalism, but also themselves become imbued with facticity (Van Maanen \& Pentland, 1994; Hull, 2012). Organizational actors come to accept them as the micro-facts of performance, not from external compulsion anymore but from the internalization of its logic. This recursive formative process is represented in summary form by figure 1, which takes audit trail subprocesses $[\mathrm{A} \rightarrow \mathrm{B}]$ from the preceding section, combines this with a disposition-formative dimension (C), and visualises the transition from stage 1 to 3.

\section{Insert Figure 1 about here}

The precise outcome of this modelled disposition-formative process will depend on the relative strengths of the components of the formative mechanism: the collective "pull" of facticity and the resistance to primary trace reductionism. The three stage model proposes 
ceteris paribus that the former will weaken the latter over time, but the speed of transition between stages can vary. For example, where primary trace production is frequent or continuous, the pull of facticity and disposition formation is likely to be stronger and the transition between stages will be quicker. Where it is infrequent, ad hoc and competes with embedded incumbent performance accounting systems, new accounts can fail to generate organizational facticity, and their process is stalled at the first stage of weak performativity

By way of illustration, consider the following stylized but not entirely fictional “process narrative" (Langley, 1999): the CEO of a private company sends an email to a university researcher noting how her published research has helped him to make important changes to management processes. The email is a matter of personal pride for her, but little more. However, subsequently her university is subject to a new performance accounting regime and is required to report on the external impact of its research (Power, 2015).

Stage 1. The researcher now recognises that the email in question could be used as textual evidence, as a primary trace, for this new accounting requirement. She is deeply sceptical of the process and of the entire idea of accounting for external impact. She believes strongly in curiosity-driven research for its own sake, and knows that the benefits of her work to society flow in many indirect and subtle ways, including teaching, and cannot be encapsulated in something as crude as "impact". Yet she is also "strongly encouraged" by her Dean to produce a case study of her research impact based on the email and other pieces of primary evidence.

Stage 2. She receives help in preparing this account of her impact from the newly appointed "chief impact officer" and, to her surprise and pleasure, her case study - one of many submitted by her academic colleagues - receives the highest numerical score by external evaluators and contributes to the high ranking for impact of her university. Despite 
her initial scepticism she enjoys being congratulated by the Dean, who says he shares her misgivings but is delighted by the university's performance. The Dean also receives a bonus from the governing body for his performance in delivering this outcome. The researcher's perceived success in impact becomes part of both formal and informal discussions of her own performance. She is increasingly described by others as an "impactful" researcher and is seen as a source of expertise on how to expand the impact of colleagues' research. Via the case studies and the overall ranking, research impact as a policy value has acquired organizational facticity in the university sector.

Stage 3. The researcher, and those who she now advises as part of the "impact strategy" of her university, not only routinely attend to emails like the one she originally received but also actively seek them from a new class of "users" of their research. They enjoy being recognised as "impactful" and emails are valued as legitimate traces of the micro-facts of research performance. She has become committed to collecting and editing them to be auditable for the impact officer and any possible external inspection. The original email from the private organization which used the research has been transformed ontologically into a "primary" trace in an audit trail process and used systematically to produce a new class of performance facts.

Good theoretical models represent a process like the one above "as if it happens in a certain way and necessarily suggest further questions" (Swedberg, 2014: 26). The fit between the process model of the audit trail logic and the narrative illustration above is not, and never can be, perfect. But the illustration is also rich enough to suggest that performance accounts production and disposition formation are likely to be strongly associated in the way that the model predicts. It shows how organizational agents may go beyond external pressures to produce new accounts. As organizations develop accounting infrastructure, they internalise and amplify these requirements in the process of adoption. 
The concept of disposition has been used to open up the "black box" of microfoundations (Powell \& Rerup, 2017) of the audit society yet, as the stylized example also shows, it is itself a black box or "placeholder" concept for more embedded processes. For example, the illustration suggests how habits and dispositions may be formed or “imprinted" at particular moments of sensemaking (Marquis \& Tilcsik, 2013) rather than as a smooth function of enactment. In addition, while the example illustrates the model, it also points to, but abstracts from, the discursive processes (Phillips et al., 2004) and language games (Astley \& Zammuto, 1992) of organizational performance accounting within which the audit trail process is embedded (Fauré, Brummans, Giroux \& Taylor, 2010). The researcher in the illustration is eventually drawn to audit trails of impact and seems to internalize their logic, but there are also likely to be counter-dispositions and competing forms of facticity at stake. We should expect this when new performance accounts are introduced into complex organizational settings in which multiple performance values and their forms of accounting exist (Thornton et al., 2005; Kraatz \& Block, 2008).

Despite these inevitable qualifications and the model's simplifications of actor sensemaking, discourse and psychology, it draws attention to a feedback mechanism by which the audit trail process entangles and constitutes organizational agents. Its logic cumulatively and repetitively (Berger \& Luckman, 1966) exerts a disciplinary power over them. They come to feel not just compelled but motivated to reproduce this logic, even when core organizational values may be at stake. The "anxiety" of organizational actors identified by Espeland and Sauder (2016) can be grounded in the dynamics of this model as a residual form of "push". Its key insight, adapted from accounting sociology, is that the emergence of performance facticity is disposition-formative via the much neglected mediating role of primary trace production. 
The model also explains why, far from minimizing inspection via practices of decoupling as Meyer and Rowan (1977) famously suggest, organizational agents, including Selznick's (1957) leaders and Espeland and Sauder's (2009) Law School Deans, are part of an endogenous process by which they come to embrace the logic of the audit trail, the performance accounts it produces, and the resulting organizational facticity of performance. It shows how the audit trail process is institutional in the sense of being a self-regulating and socially-constructed mechanism which also enforces and expands its own application (Jepperson, 1991: 145; Phillips et al., 2004: 638). However, we need to refine the claims of the model one step further in order to be more precise about its amplifying and diffusing nature.

\section{From Audit Trail "Token" to "Type"}

At the micro-level of organizations and groups of organizational actors, the disposition to reproduce audit trails is necessarily a disposition formed within specific performance accounting settings, such as impact accounting described in the previous section. It was also noted earlier that any number of performance values can motivate the production of specific performance accounts, and organizational actors engage in institutional work to create, improve, maintain and even destroy them (Battilana, Leca \& Boxenbaum, 2009; Lawrence et al., 2009; Bromley \& Powell, 2012: 500). Indeed, there are often intense arguments about how best to account for values such as diversity or sustainability, and there can be fierce competition between different performance accounts and the facts they produce. All these important issues concern specific audit trail "tokens".

Yet, in the transition from weak to strong performativity, the disposition being formed is an orientation to reproduce the abstract meta-logic or "type" of the audit trail in any specific performance accounting setting, regardless of content. This notion of type is 
analogous to that of a "deep grammar" (Wittgenstein, 1976, para. 664) in that it is a condition of possibility for "auditable" performance account construction in general which requires the sequential production of aggregate representations of performance from primary traces. However, this logical distinction between token and type must now be reframed within our model as a dynamic process of abstraction in which type emerges from token.

Within each specific audit trail setting organizational actors form a disposition to reproduce both the specific token of the logic of the audit trail and also its abstract type, its logical form. By definition, the specific token is contingent and can fail or be reformed without necessarily damaging the emerging disposition to reproduce the logical form or type. This meta-logic or type is both more durable than its empirical tokens and can also diffuse well-beyond them (Meyer \& Strang, 1993). It is less discretionary than the form and content of specific performance accounts. Deviations from, and resistance to, it will impose economic, cognitive and legitimacy costs on organizational actors (Phillips et al., 2004) because they violate cultural norms and the bundle of myths embodied in its logic.

A more dynamic and formative reading of the well-known distinction between token and type suggests the that the seemingly exogenous organizing myths revealed at the socalled "macroinstitutional" level of analysis, and which are assumed to set in motion pressures at the organizational level, are themselves generated and sustained from the microlevel of accounts production. In other words, the strongly performative model of the logic of the audit trail is also an abstraction "engine" which is productive of the rational myth of itself at the macro-level. This is consistent with other models of micro- to macro-level endogeneity and mutuality, such as studies of behaviour and meaning formation (Cornelissen, Durand, Fiss, Lammers \& Vaara, 2015; Zucker, 1977), the dynamics of institutional logic formation and availability (Thornton et al., 2012: 85) and the mutually formative relation between habitus and field (Butler, 1999: 117). Moreover, we can now position the formative model of 
audit trails as a micro-level of analysis, which is not a proposed "solution" to the structureagency problem but is itself a theory of the generative core of a multi-layered whole (Cardinale, 2018; Harmon et al., in press).

In summary, we have developed a performative model of the microfoundations of the audit society. This model shows how the audit society is the macro-outcome of a microprocess which embeds itself in organizations via the repeated production of audit trails. This process co-produces both performance facticity and the dispositions of organizational actors which sustain that production. The strongly performative form of the model shows how the logic of the audit trail is a self-fulfilling, self-regulating and self-amplifying meta-logic or "type" which expands the range of situations in which it can be applied (Jepperson, 1991; Marti \& Gond, 2018). It shows how organizations adopt and amplify performance reporting systems regardless of whether they are ineffective or counterproductive or value subversive. This disposition-generating property of audit trails goes beyond an inability to resist, or the passification of organizational agents in settings of hierarchical power. Rather, the model proposes that the much criticised audit society and its pathologies is the outcome of a strong collective disposition towards the facticity generated by audit trails which progressively nullifies the reflexive critique of organizational actors. This model of the performative power (Marti \& Gond, 2018) of the logic of the audit trail supports the core theoretical proposition of this article:

Proposition 1: the more that organizational actors enact the audit trail process, the more that performance accounts acquire organizational facticity, and the more that these actors become disposed to reproduce and expand the logic of that process, despite evidence of value subversion.

\author{
DYNAMICS AND VARIATION
}


In this section, we fine-tune the audit trail model and core proposition 1 above by considering four possible sources of variation which influence the strength, direction and timing of the performativity of the logic of the audit trail, and therefore its persistence and amplification.

\section{Primary Trace Production and Work Processes.}

As noted earlier, primary traces are reductive representations of performance and the artefactual building blocks for organization-level accounts of performance (cf D'Adderio, 2008). They are systematically collected, classified, commensurated, made combinable and aggregated (Espeland \& Stevens, 1998; Mennicken \& Espeland, in press). However, the disposition-forming dynamic expressed in proposition 1 will vary according to the extent to which new primary traces are experienced by organizational actors as continuous with preexisting practices of performance accounting. There may be more or less stage 1 "push" against the reductionism of primary traces from organizational actors depending on whether they are already engaged in producing them.

As Gawande (2010) notes in his popular tribute to the checklist, the take-off-readiness protocol used by airline pilots is accepted as fundamental to their operating routines. The "tick" which is entered into a check-box as an on-board "control action" by a pilot simultaneously creates a trace for an audit trail. Modifications, and even expansions, of their checklists are unlikely to be systematically resisted by pilots since they are normally designed by pilots themselves, and align with existing patterns of working. Checklists are both functionally useful to pilots and are also an inscription of pilot and airline performance. Even where primary performance data is created by third parties, such as the use of questionnaires to measure "student satisfaction" and "patient experience" (Pflueger, 2016), organizational actors may experience this as continuous with normal feedback and learning 
processes. Furthermore, organizational actors may be more likely to embrace the reductivism of new primary trace requirements when they are involved in their design (Falk \& Kosfeld, 2006).

The situation is likely to be different with radically new performance demands (Dent, 1991; Townley, 1997), such as requirements to account for the external impact of research by universities mentioned in the previous section, or the need for banks to demonstrate good culture (Palermo, Power \& Ashby, 2017). In these circumstances organizational actors will be initially less receptive to the reductivism of audit trail requirements and the facticity of performance accounts will be weaker. Where primary trace and reporting requirements have little or no continuity with existing work practices, they may even encourage deviant behaviour, such as creating the required traces ("box-ticking") without the substantive performance (Baxter \& Clarke, 2013). Where the reductivism of primary traces receives very strong push back, pressure is also created to design "better" primary traces.

In summary, the performative strength and persistence of the logic of the audit trail as summarised in the core proposition will vary depending on whether newly demanded primary traces at stage 1 have a low-push, "high cultural fit" (Marti \& Gond, 2018; Ansari et al., 2010: 78) with current work practices. On the one hand, the lower the cultural fit between audit trail production work and other work (Power, 2016), the more likely it is that organizational agents will initially push back and try to decouple new reporting requirements, leading to weak performativity and the delayed or even rejected facticity of such accounts and their primary traces. On the other hand, prior experience matters. Where organizational actors have developed low push against the logic of the audit trail for a specific token, it is more likely that they will have low push for any subsequent token of performance accounting to which they are exposed. Yet even the power of this accumulated experience may be diluted where organizational actors who are generally disposed to reproduce the logic of the 
audit trail as a type nevertheless resist particular tokens of that logic because they are too dissonant with existing practice. Thus, while proposition 1 argues that the power of the logic of the audit trail process to generate performance facticity will erode strategies of decoupling and resistance at stage 1 over time (Boxenbaum \& Jonsson, 2017), its dynamics can be modified in the following sub-proposition to recognise these frictions:

Proposition 1.1: the less (more) that organizational actors experience specific primary trace requirements as continuous with existing work practices and values, the stronger (weaker) the push-back and the weaker (stronger) will be the facticity-pull and disposition-forming effects of audit trails.

The expansion of digital platforms, such as TripAdviser, means that consumers create primary traces of performance, such as satisfaction scores, when they rate hotels, holidays and restaurants. The general public is empowered as a direct evaluator and, much like the case of law school rankings (Sauder \& Espeland, 2009), this stimulates evaluated organizations to track primary traces of customer satisfaction and produce summative metrics and accounts (Jeacle \& Carter, 2011; Orlikowski \& Scott, 2014). TripAdviser and similar engines are therefore an increasing source of digitized audit trail construction as organizations seek to manage how they are rated and ranked.

Organizational actors increasingly use digital platforms to engage in evaluation and audit activity outside the workplace. Indeed, trace creation and traceability are now features of everyday life as people quantify, monitor and evaluate many aspects of their personal lives, such as health and educational attainment (Sharon \& Zandbergen, 2017; Mennicken \& Espeland, in press). The anxious law school Deans interviewed by Espeland and Sauder (2016) most likely use rankings and ratings as diners choosing a restaurant, or as parents choosing a primary school for their children. As the audit society has evolved, the distinction between expert auditor and auditee, evaluator and evaluatee, rater and rated has become blurred; monitoring and being monitored are an increasing part of everyday experience. It is 
therefore likely that organizational actors will already have a pre-disposition to reproduce reductive primary traces, and will accept the facticity they produce, when they are also engaged in similar activity in their personal lives e.g. as "disciplined selves" monitoring their own health, refining their CVs, rating restaurants, films and other leisure experiences, as well as choosing schools (Lupton, 2016; Esposito \& Stark, in press). Accordingly, we can add an amplifying/dampening moderation to the core proposition 1 as follows:

Proposition 1.2. The more (less) that organizational actors enact forms of auditing and evaluation in non-work settings, the weaker (stronger) their push-back against reductivism and the quicker (slower) the emergence of the strong performativity of audit trails in organizational work settings.

\section{Blame and Amplification}

Studies of legalization, understood as the growth of law-like forms, such as due process, show why organizations may “overcomply" and internally amplify external requirements (Argyris, 1994). These studies show that organizational actors exhibit a defensive "litigation mentality" (Bies \& Tyler, 1993; Sitkin \& Bies, 1994), and keep detailed records "just in case" (Van Maanen \& Pentland, 1994). By analogy, audit trail requirements will also be amplified by organizational actors in institutional environments where there is personal legal risk or reputational exposure to censure from both regulatory bodies and civil society organizations In such settings where blame is anticipated, organizational actors will manage accounting disclosures strategically (Marquis et al., 2016) and also, in parallel, will devote effort to creating and maintaining audit trails as evidence of compliance. They will make primary traces more precise, more elaborate and more rationalized than formally required. Thus, rather than critically pushing against the reductivism of primary traces in stage 1 , they are already defensively pre-disposed to amplify their precision as auditable traces of performance. For example, in reacting to the Sarbanes-Oxley legislation ("Sarbox") following the collapse of Enron and Worldcom, organizations and their advisers elaborated 
primary traces (of internal controls) greatly in excess of formal requirements (Economist Leader, 2003; SEC, 2005).

Organizational studies of legalization, which focus on these defensive properties of precise documentation, explain why there is both strategic acquiescence (Oliver, 1991) to the logic of the audit trail and also amplification of its requirements in specific cases like Sarbox. Audit trails and their primary traces can become valued for their own sake by organizational actors who are averse to the risk of blame. Rather than resisting the reductionism of new performance requirements at point of adoption, these organizational actors are more likely to amplify and elaborate them from the outset. This pre-existing defensive disposition will accelerate the transition to the strong performativity of audit trails.

Proposition 1.3: the more (less) that organizational actors believe that they face possible censure and blame, the more (less) that they will embrace, elaborate and amplify audit trails, and the weaker (stronger) will be the "push" against primary trace reductivism.

\section{Agents of Amplification}

Habits and dispositions are formed interactively (Turner \& Cacciatori, 2016) and therefore the collective organizational context of audit trails will influence the nature and extent of their performativity. In particular, different performance accounts in large organizations are normally produced by specialised individuals in sub-units, such as finance and risk management departments, with varying degrees of internal positional power and influence. These individuals occupy subject-positions which mediate, interpret and operationalise regulatory and other performance requirements (Gray \& Silbey, 2014). They acquire influence by building reporting infrastructures which embed audit trail processes and they become willing carriers and enforcers of its logic. Their internal authority is reinforced by their participation and credibility in wider field and professional networks (Hinings, Logue \& Zietsma, 2017) and invisible trans-organizational "colleges" (Lampel \& Meyer, 2008) which promote performance accounts. These professionals also circulate around these 
networks - sometimes as regulators, sometimes as advisers, sometimes as sub-unit actors and are carriers of audit trail logic to different settings. For example, in their study of risk culture, Palermo et al. (2017) noted how the circulation of professionals across private firms, regulatory bodies and consulting organizations led to similar diagnoses and audit trail-based solutions for the problem of improving and reporting on risk culture. In this way, the strong performativity of audit trails is accelerated by organisational actors with positional power to share and diffuse practice within and across organizations.

These actors operate in complex internal organizational environments (Bromley \& Powell, 2012: 499; Greenwood, Raynard, Kodeih, Micelotta \& Lounsbury, 2011) and their positional power may be an outcome of “organizational rivalry” (Selznick 1957:9-10) as much as perceived expertise (Gray \& Silbey, 2014). They are also likely to use external events as opportunities for internal positioning and resource expansion (e.g. Kelly \& Dobbin, 1998). For example, the regulatory and reporting responsibilities of senior management and directors of companies, such as under Sarbox, have grown considerably over the past two decades, making them important internal clients for specialised internal actors. These regulatory pressures to demonstrate the good governance of risks, such as financial crime (Favarel-Garrigues, Godefroy \& Lascoumes, 2011) and failure to treat customers fairly (Gilad, 2011), reinforces both the positional power of risk managers and compliance officers and also the logic of the audit trails by which they make these risks auditable and governable. In contrast, "diversity officers", who may be limited to operationalising the performance of diversity as an annual half day awareness training session, may not acquire this kind of positional power. Their primary traces for regulatory compliance with diversity requirements might only be the training attendance certificates of organizational members. The weak performativity of an audit trail is therefore likely to be correlated with weak the positional power of its relevant internal representatives (cf Kalev, Dobbin \& Kelly, 2006). 
In sum, the performativity of audit trails will be modulated by, and will in turn modulate, the presence of convinced organizational actors in specialised sub-units with positional power. At its strongest, the logic of the audit trail generates the dispositions of its own champion-subjects who reinforce that logic and are empowered as sensegivers to speak on behalf of, and operationalise, culturally validated conceptions of performance accounting. We capture one direction of this mutual influence in the following proposition:

Proposition 1.4: the stronger (weaker) the internal positional power of members of specialised performance accounting sub-units, the faster (slower) to emerge is the strong performativity of the audit trails which they promote, create, sustain and amplify.

Taken together, the core proposition and the four selected variants outlined above, though not exhaustive of all possibilities, provide an orientation for empirical enquiry into the dynamic properties and implications of the core model (Cornelissen, 2017). They are testable hypotheses in their own right and articulate contingent variations which may accelerate or delay the pathway to the strong performativity of audit trails. The propositions are also symmetrical in that they articulate factors which may strengthen or weaken the core proposition. For example, where primary traces are regarded as too reductive and "unrealistic"; and organizational actors do not act as evaluators in their everyday lives; and the setting is free from potential blame; and specialised carriers are either weak or nonexistent, then the pull of facticity and the strength of disposition formation in respect of specific audit trail tokens will be weak. The fact that such settings, while logically possible, are difficult to imagine reinforces the strong performativity of the core thesis. Yet, even in such a counter-setting, could we imagine it, the institutionalising power of the logic of the audit trail as a type would not necessarily be undermined by a single counter case or token.

\section{FROM "VALUE SUBVERSION" TO "VALUES AT RISK"}


While the performative model of the logic of the audit trail provides a specific micro-level explanation of how the audit society persists and expands, it also has broader implications. A crucial feature of the theorized formative process is the production of accounting facticity and the "pull" it exerts over organizational actors (Durkheim, 1982). In this respect, an unexpected contribution of the model is to allow us to think of the audit trail "neutrally" as a mechanism by which abstract policy values become coupled to organizational routines and acquire an organizational facticity, via accounting, that they might otherwise lack. From this perspective, the reductive and facticity-producing potential of audit trails need not be regarded as inherently pathological. For example, Wijen $(2014 ; 2015)$ argues that the risks of means-end decoupling as Bromley and Powell (2012) describe them (and the value-inversion which preoccupies the critics of the audit society) must be traded off against the possible benefits of acquiring organization traction for important policy values, such as sustainability.

Anticipating critics of the audit society by several decades, Selznick also understood this trade-off very clearly. The formative model of the audit trail developed in this article helps to articulate the dynamics of this trade-off in accounting terms. Following Selznick, we can say that opaque organizational or policy values necessarily require "completing" (Selznick, 1996:273) by being operationalised in technical routines; values and technical tasks like accounting are therefore interdependent (Besharov \& Khurana, 2015). Indeed, core organizational values at risk of subversion are not themselves externally given as ends and immune from social construction (Haack \& Schoeneborn, 2015; Wijen, 2015). Even Friedland (2017), as a value transcendentalist, reminds us that values lack any capability for self-manifestation outside of the material practices which presume and perform them. Abstract values like transparency must of necessity undergo "risky" operationalizations (Bernstein, 2017) or they will never acquire the opportunity for organizational facticity. This means that when the theory of "means-end "decoupling is expressed in a formative model of 
the kind developed for audit trails, it is better understood as a theory of means-end coformation and coupling. The logic of the audit trail performs both means - primary traces and the disposition to reproduce them - and ends in terms of producing the organizational facticity for values. The audit trail is therefore a mechanism with strongly performative potential for institutionalising values but they are always and necessarily "values at risk".

In conclusion, the facticity-formation dynamic of the core model is open-ended. In some settings it is crudely reductive of the lived complexity of actual work processes and performance, and threatens pre-existing professional identities (Townley, 1997; McGivern \& Ferlie, 2007) - well-documented audit society effects. And yet, even seemingly crude accounting measures such as student satisfaction metrics in schools, which risk distorting pedagogic values of development via the dynamics of means-end decoupling, may nevertheless create needed facticity for the value of the student experience and enable decision making under uncertainty (Esposito \& Stark, in press). Indeed, the much criticised Sarbanes-Oxley legislation introduced in the United States in 2003, to which, as already noted, organizations reacted defensively by amplifying requirements into a formal "boxchecking" exercise, did eventually create public visibility for the value of internal controls in organizations. Over time a new class of performance facts - control facts - was created to materialise this value. The core model therefore shows that while values are always at risk because they are shaped by reductive primary trace production, performance accounting can give these values the organizational facticity, and therefore traction, that their advocates desire.

\section{DISCUSSION AND IMPLICATIONS}

The model of the audit trail developed above articulates a generative process which shows how audit trails are self-fulfilling. While macro-institutional theories explain why 
organizations adopt new accounting and audit requirements in accordance with a bundle of rational myths of control and performance, the model and its further propositional refinements show both how this happens and also why they are likely to be strongly performative and self-amplifying. This is in effect a microfoundational model of the audit society which shows how the audit trail process can lead to the progressive reshaping and inversion of organizational goals and core values (Selznick, 1957) in excess of formal regulatory intention. The model grounds an endogenous formative process in which institutionalised means like accounting develop their own ends and become decoupled from policy values (Pache \& Santos, 2010: 460; Bromley \& Powell, 2012). This phenomenon is well-recognised in social theory, was one of the central preoccupations of the Frankfurt School under the motif of "dialectic of enlightenment" (Horkheimer \& Adorno, 2002), and is implicit in critiques of the audit society.

This article contributes to institutional theory by showing how, via the repetitive enactment of accounting, organizational actors form dispositions to produce and expand the logic of the audit trail. The model captures tensions between the so-called "pull" of accounting facticity and the "push" back against audit trail reductionism. Organizational actors are simultaneously drawn to, and repelled by, audit trails and the performance representations which they produce (Kraatz et al., 2010: 1540). However, it is proposed that the dynamics of repeated audit trail production eventuate in a strongly performative version of the model. In other words, the "pull" of performance facticity eventually "crowds-out" (Frey \& Jegen, 2001) reflexive critical reservations about the reductive and unrealistic nature of primary traces. This strong version of the model therefore explains why value-subverting accounting systems, far from being decoupled, become strongly coupled, amplified and expanded. In conclusion, four more specific contributions of the model, and its limitations 
and possible implications for future theoretical and empirical research, are considered further below.

\section{The Dynamics of Facticity}

In explicating the microfoundations of the audit society, we find, surprisingly perhaps, elements of a formative process which are not inherently pathological. The strongly performative "pull" of accounting facticity may potentially operate to "crowd in" values as much as crowd them out. As institutional thinkers as diverse as Selznick and Friedland recognise, the values we care about are inherently precarious in that the moment of their operationalisation also places them at risk. The model of the logic of the audit trail therefore contributes to the recent "Selznickian" turn in organization studies by emphasising an important dynamic relation between values and accounting. On the one hand, accounting can be value distorting via the economization of organizations - the audit society thesis. Yet, on the other hand, accounting, via the mechanism of facticity production, can be valuepromoting.

More theoretical work is needed to develop and tighten the construct of facticity and its relation to value. Empirical studies could usefully enrich the interactive and discursive processes (Phillips, et al., 2004) by which the facticity of organizational performance accounts is progressively constructed. There also remain questions about the nature of the general allure or "pull" of accounting facticity, such as the organizing power of ratios (Kurunmäki \& Miller, 2013) and rankings (Espeland \& Sauder, 2016; Esposito \& Stark, in press). More work is specifically needed to understand how facticity, as an experience of otherness, may itself be grounded in a more fundamental disposition to externalise and treat numbers and accounts as being about the world. The performative model of the audit trail points to the significance of such a process but it invites further specification. This further 
work should return to the phenomenological origins of the concept of facticity and reconstruct its influence through ethnomethodology and studies of sensemaking in order to enrich the category of "pull". In strong form the model proposes that the "push" against reductive and simplifying performance representations is somehow eliminated by the pull of accounting facticity. Yet, contra the model, it seems unlikely that critical reflection would be entirely suppressed. Future research could challenge the model's simplifications and develop our understanding of the power of audit trails to constitute less unified selves (Butler, 1999) which remain critically-reflective, while preserving the formative insights of strong performativity.

\section{Developments in Digitization}

The implications of developments in digital technologies, such as blockchain and big data, for the logic of the core model have been glossed over but require careful future consideration. Indeed, if the cultural and organizational position of performance accounts, as aggregations of determinate primary data, declines, then the theoretical power of the model will be significantly diminished. But this remains an open question. On the one hand blockchain promises to expand the range of objects which can be accounted for and traced, provided they can be digitally and uniquely tagged. In this sense blockchain elevates the audit trail logic from meta-logic into an end in itself. Blockchain, as traceability made explicit and digital, radicalises the model and provides a platform for new performance accounts and new facticities for values such as "sustainable fishing" (Power, in press). On the other hand, the sheer plurality and heterogeneity of primary traces which comprise big data and its predictive analytics may make conventional forms of organization-level accounting redundant. With big data, any primary trace can be related to any other to generate new patterns and predictive capabilities. Accordingly, work is needed to explore 
whether and how developments in digital technologies will mean that audit trail processes in organizations will intensify, mutate or be displaced.

\section{Meta-Logics}

A third area for future development is the claimed meta-logical status of the audit trail, which has implications for thinking about institutional complexity. Not only do organizational agents often have to navigate the binary complexity of different values and their trade-offs, such as education versus efficiency; professionalism versus commercialism (Thornton et al., 2005; Greenwood et al., 2011), but also, under societal conditions of expanded performance reporting requirements for these different values (Bromley \& Powell, 2012), the meta-logic of the audit trail must be added to the "complexity mix". However, as noted, the logic of the audit trail is not simply one logic among others competing for priority in a plural world of well-formed logics. Its status is not that of a "toolkit" to be chosen more or less reflectively by agents (McPherson \& Sauder, 2013: Pache \& Santos, 2013). Rather, as a meta-logic it is the basis by which these other logics - institutional logics (Friedland \& Alford, 1991: 248) and their existential values (Mutch, 2018) - can be made operable, and observable (Palermo et al., 2017). In short, via performance accounts, this meta-logic is productive of the organizational facticity of these other logics.

Building on this notion of a meta-logic could also shed more light on how logics are not only plural but also varied in their amenability to strategic choice. Logics which are amenable to choice and discretion are more likely to lead to situations of institutional complexity requiring trade-offs and choice (Kraatz \& Block, 2008; Pache \& Santos, 2010; 2013). However, by construction the meta-logic of the audit trail is less discretionary than this. It has been suggested that it has grammar-like status. Just as grammars define what it is to speak competently in a specific language, the repeated grammatical use of a language also 
reinforces the grammar. By analogy, the meta-logic of the audit trail is a condition for the production of competent performance accounting which in turn reinforces it. Yet unlike a grammar, the meta-logic of the audit trail is biased towards auditability and this will influence choices under conditions of institutional complexity where one value or institutional logic seems more "auditable" than the other (Palermo et al., 2017).

Accordingly, future work could focus more on how the meta-logic of the audit trail is not neutral in situations of multiple logics and institutional pluralism, and may influence the "centrality" of one logic over another (Besharov \& Smith, 2014), exactly as we see in the audit society. Indeed, it could be fruitful to characterise institutional pluralism as a "competition of facticities" where the power over accounts production is a key strategic stake.

Future work could also explore meta-logics more generally and show how the logic of the audit trail is one of a family of meta-logics with grammar-like status. For example, another plausible candidate for meta-logic status is the notion of "due process" as it has evolved within and beyond law (Edelman, 1990; Edelman, Uggen \& Erlanger, 1999). Like the logic of the audit trail, it is also seemingly procedural and content-neutral, and is widely diffused in non-legal settings as a vehicle for the legalization of organizations. Indeed, there are likely to be deep affinities between law and accounting at the level of micro-processes which are worthy of examination and which suggest further lines of theory development.

\section{Amplification, Diffusion and Audit work}

Finally, the strongly performative version of the model shows how dispositionformation and abstraction are mechanisms of practice diffusion and expansion, which begin with amplification at the organizational level. While disposition formation creates new subject-positions as carrier-agents, the abstract form of the logic (Strang \& Meyer, 1993) 
enables rapid diffusion to new performance settings, including those of the carriers themselves, who are "infected" by it. For example, while professional service firms are in some sense the manifest agents of the expansion of the logic of the audit trail (Suddaby et al., 2007), the strongly performative model of its diffusion shows how this logic becomes both independent of their agency and also recursively determinative of it. In other words, auditors, regulators and other oversight bodies are as much subjects of this logic as they are its carriers. This can be observed: while there are certainly more auditors, evaluators and overseers in the audit society (Hood, James, Jones, Scott \& Travers, 1998), these carriers of audit trail logic are also subject to its cultural power in the form of requirements to produce primary traces of their work (Pentland, 1993; Van Maanen \& Pentland, 1994). This seeming "reverse diffusion" of audit trail logic deserves more attention.

The model has inevitably taken some short cuts in its specification of microfoundations. There is a danger within the model of over-identifying the micro-level with individual human actors (Harmon et al., in press), and thereby making the mechanics of logic amplification too individualistic. The model's central concept of disposition remains "thinly social" and does not situate organizational actors in relational webs of action (Emirbayer \& Mische, 1998). This limitation is important because organizations are likely to be saturated in audit trails relating to different performance representation requirements. Organizational actors are confronted by multiple audit trails and interact in multi-actor settings. Future work could therefore situate the micro-analysis of audit trail production within richer notions of practice and practice formation (Pentland, 1993; Vaara \& Whittington, 2012:287), paying attention to the role of organizational actors with positional power in amplification processes.

In addition, the formative model of audit trails invites greater integration and specification in conjunction with routines theory (Feldman \& Pentland, 2003; D'Adderio, 2008; Cacciatori, 2012; Powell \& Rerup, 2017: 313) to understand how the emergence of 
performance reporting routines may shift collective dispositions. An empirical programme could usefully explore a new category of institutional work, namely "audit work" understood as the routinized work of organizational actors to represent, report and evaluate performance (Power, 2016). Indeed, the intensity of audit society could in theory be measured by the proportion of total work which is audit work in this sense, at the level of the individual, organization and field.

Finally, it must be acknowledged that a strongly performative model of disposition formation exists in tension with theoretical emphases on leadership (Kraatz, 2009). Strong performativity leading to audit society persistence seems to be at odds with the kind of leadership which Selznick envisaged, making the latter at best an epiphenomenon of a deeper formative process. Yet, if we follow Selznick and those who are reviving his work on the significance of values in organizations (Besharov \& Khurana, 2015), it is a core task of leadership to manage and mitigate the risks of value subversion and pluralism, and to generate facticity for organizational mission and purpose. There is therefore work to be done to address both this theoretical tension and also the practical challenges for leaders and regulators who wish to utilise performance accounting systems while also controlling their value-subverting effects (Selznick, 1957; 7; Kraatz at al., 2010). To face up to these challenges, leaders will need to understanding how the audit society actually works and pay attention to the formative power of audit trails.

\section{CONCLUSION}

At first glance, audit trails appear of limited theoretical and empirical interest. Yet, this article has shown that they embody a formative logic which is powerful precisely because it is mundane and invisible (Douglas, 1986:98). This logic has expanded well beyond financial accounting to shape an explosion of performance accounts of many different kinds. 
Its mechanism is central to contemporary modes of defining, representing and intervening in the performance of individuals and organizations, and shapes them as "auditable subjects" committed to reproduce its logic. While the primary motivation for developing this model was to ground the microfoundations of the so-called audit society and its pathologies in a generative mechanism which explains its persistence, we also find that value inversion and means-end decoupling are not inevitable. We cannot therefore ignore the possibility that audit trails may sometimes be efficacious policy instruments for embedding values, economic or otherwise, in organizations. For this reason they deserve more theoretical and empirical attention by scholars, regulators and policy makers. 


\section{REFERENCES}

Abbott, A. 1995. Things of boundaries. Social Research, 62(4): 857-882.

Accounting Tools (2018). Audit trail.

https://www.accountingtools.com/articles/2017/5/7/audit-trail?rq=audit\%20trail

Accessed $17^{\text {th }}$ January 2019.

Adler, P. S. \& Borys, B. 1996. Two types of bureaucracy: Enabling and coercive.

Administrative Science Quarterly, 41(1): 61-89.

Allcott, H. \& Gentzkow, M. 2017. Social media and fake news in the 2016 election. Journal of Economic Perspectives, 31(2):211-36.

Ansari, S. M., Fiss, P. C. \& Zajac, E. J. 2010. Made to fit: How practices vary as they diffuse. Academy of Management Review, 35(1):67-92.

Argyris, C. 1994. Litigation mentality and organizational learning. In S. Sitkin \& R. Bies (Eds.) The legalistic organization: 347-58. Thousand Oaks, Ca: Sage.

Astley, W. G.\& Zammuto, R. F. 1992. Organization science, managers, and language games. Organization Science, 3(4): 443-460.

Barnes, B. 1983. Social life as bootstrapped induction. Sociology, 17(4): 524-545.

Barney, J. \& Felin, T. 2013. What are microfoundations? The Academy of Management Perspectives, 27(2): 138-155.

Battilana, J., Leca, B. \& Boxenbaum, E. 2009. How actors change institutions: towards a theory of institutional entrepreneurship. Academy of Management Annals, 3(1): 65-107. Baxter, J. \& Clarke, J., 2013. Farewell to the tick box inspector? Ofsted and the changing regime of school inspection in England. Oxford Review of Education, 39(5):702-718. 
Berger, P. L. \& Luckmann, T. 1966. The social construction of reality: A treatise in the sociology of knowledge. NY: First Anchor.

Bernstein, E. 2017. Making transparency transparent: The evolution of observation in management theory. Academy of Management Annals, 11 (1): 217-266.

Besharov, M. L. \& Smith, W. K. 2014. Multiple institutional logics in organizations:

Explaining their varied nature and implications. Academy of Management Review, 39(3): 364-381.

Besharov, M. L. \& Khurana, R. 2015. Leading amidst competing technical and institutional demands: Revisiting Selnick's conception of leadership. In M. Kraatz (Ed.) Institutions and ideals: Philip Selznick's legacy for organizational studies: 53-88. Emerald Group Publishing Limited.

Bevan, G. \& Hood, C. 2006. What's measured is what matters: targets and gaming in the English public health care system. Public Administration, 84:517-538

Bies, R. J. \& Tyler, T. 1993. The litigation mentality in organizations: A test of alternative psychological explanations. Organization Science, 4(3): 352-366.

Bourdieu, P. 2010. Distinction: a social critique of the judgement of taste. Transl. R. Nice (1984). London \& NewYork: Routledge.

Boxenbaum, E. \& Jonsson, S. 2017. Isomorphism, diffusion and decoupling: Concept evolution and theoretical challenges. In R. Greenwood, C. Oliver, T. Lawrence, \& R. Meyer (Eds.). The Sage handbook of organizational institutionalism: 79-104.

Bromley, P. \& Powell, W. 2012. From smoke and mirrors to walking the talk: decoupling in the contemporary world. The Academy of Management Annals, 6: 483-530. 
Bromley, P. \& Sharkey, A. 2017. Casting call: The expanding nature of actorhood in US firms, 1960-2010. Accounting, Organizations and Society, 59: 3-20.

Burchell, S., Clubb, C., Hopwood, A., Hughes, J. \& Nahapiet, J. 1980. The roles of accounting in organizations and society. Accounting, Organizations and Society, 5(1): 5-27.

Butler, J. 1999. Performativity's social magic. In R. Shusterman (Ed.) Bourdieu: A critical reader: 113-128. Oxford: Blackwell Publishers.

Butler, J. 2010. Performative agency. Journal of Cultural Economy, 3(2):147-161.

Cacciatori, E. 2012. Resolving conflict in problem-solving: systems of artefacts in the development of new routines. Journal of Management Studies, 49(8):1559-1585.

Callewaert, S. 2006. Bourdieu, critic of Foucault: The case of empirical social science against double-game-philosophy. Theory, Culture \& Society, 23(6): 73-98.

Callon, M. 1998. Introduction: the embeddedness of economic markets in economics. The Sociological Review, 46(S1): 1-57.

Camic, C. 1986. The matter of habit. American Journal of Sociology, 91(5): 1039-1087.

Cardinale, I. 2018. Beyond constraining and enabling: Towards new microfoundations for institutional theory. Academy of Management Review, 43(1): 132-155.

Chapman, C. S., Cooper, D. J. \& Miller, P., 2009. Linking accounting, organizations, and institutions. In C. S. Chapman, D. J. Cooper \& P. Miller (Eds.), Accounting, organizations and institutions: 1-29. Oxford: Oxford University Press.

Christensen, L. T. \& Cornelissen, J. 2015. Organizational transparency as myth and metaphor. European Journal of Social Theory, 18(2): 132-149. 
Cohen, M. D. 2007. Reading Dewey: Reflections on the study of routine. Organization Studies, 28(5): 773-786.

Cohen, M. D. 2012. Perceiving and remembering routine action: Fundamental micro-level origins. Journal of Management Studies, 49(8): 1383-1388.

Cooper, A. 2001. The state of mind we're in: Social anxiety, governance and the audit society. Psychoanalytic Studies, 3(3-4): 349-362.

Cooren, F. 2004. Textual agency: how texts do things in organizational settings. Organization, 11(3):373-393.

Cornelissen, J. 2017. Editor's comments: developing propositions, a process model, or a typology? Addressing the challenges of writing theory without a boilerplate. Academy of Management Review, 42: 1-9.

Cornelissen, J. P., Durand, R., Fiss, P. C., Lammers, J. C. \& Vaara, E. 2015. Putting communication front and center in institutional theory and analysis. Academy of Management Review, 40(1): 10-27

Cronin, C. 1996. Bourdieu and Foucault on power and modernity. Philosophy \& Social Criticism, 22(6): 55-85.

Crossley, N., 2013. Habit and habitus. Body \& Society, 19(2-3): 136-161. D'Adderio, L. 2008. The performativity of routines: Theorising the influence of artefacts and distributed agencies on routines dynamics. Research Policy, 37(5): 769-789.

Dambrin, C. \& Robson, K. 2011. Tracing performance in the pharmaceutical industry: Ambivalence, opacity and the performativity of flawed measures. Accounting, Organizations and Society, 36(7): 428-455. 
Dent, J. F. 1991. Accounting and organizational cultures: a field study of the emergence of a new organizational reality. Accounting, Organizations and Society, 16(8): 705-732.

Dewey, J. 1922. Human nature and conduct: An introduction to social psychology. New York: Holt.

Dick, P. 2015. From rational myth to self-fulfilling prophecy? Understanding the persistence of means-ends decoupling as a consequence of the latent functions of policy enactment. Organization Studies, 36(7): 897-924.

DiMaggio, P. J \& Powell, W. W. 1991. Introduction. In W.W. Powell \& P.J. DiMaggio (Eds.). The new institutionalism in organizational analysis: 1-38. University of Chicago Press.

Dionysiou, D. D. \& Tsoukas, H. 2013. Understanding the (re) creation of routines from within: A symbolic interactionist perspective. Academy of Management Review, 38(2): 181205.

Dirsmith, M. W. 1986. Discussion of "social environments and organizational accounting”. Accounting, Organizations and Society, 11(4-5): 357-367.

Douglas, M. 1986. How institutions think. London: Routledge.

Durkheim, E. 1982. What is a social fact? In S. Lukes (Ed.), Durkheim: the rules of sociological method: 50-59. London: Palgrave.

Economist Leader. 2003. Sox it to them. The Economist July $31^{\text {st }}$

Edelman, L. B., 1990. Legal environments and organizational governance: The expansion of due process in the American workplace. American Journal of Sociology, 95(6): 1401-1440. 
Edelman, L., Uggen, C. \& Erlanger, H. 1999. The endogeneity of legal regulation: grievance procedures as rational myth. American Journal of Sociology, 105(2): 406-54

Emirbayer, M. \& Mische, A. 1998. What is agency? American Journal of Sociology, 103(4): $962-1023$.

Espeland, W. \& M. Stevens. 1998. Commensuration as a social process. Annual Review of Sociology, 24:312-43.

Espeland, W. \& Sauder, M. 2007. Rankings and reactivity: how public measures recreate social worlds. American Journal of Sociology, 113(1): 1-30

Espeland, W. N. \& Sauder, M. 2016. Engines of anxiety: Academic rankings, reputation, and accountability. Russell Sage Foundation.

Esposito, E. \& Stark, D. In press. What's observed in a rating? Rankings as orientation in the face of uncertainty. Theory, Culture \& Society.

Falk, A. \& Kosfeld, M. 2006. The hidden costs of control. The American Economic Review 96(5):1611-1630.

Fauré, B., Brummans, B. H., Giroux, H. \& Taylor, J. R. 2010. The calculation of business, or the business of calculation? Accounting as organizing through everyday communication. Human Relations, 63(8): 1249-1273.

Favarel-Garrigues, G., Godefroy, T. \& Lascoumes, P. 2011. Reluctant partners? Banks in the fight against money laundering and terrorism financing in France. Security Dialogue, 42(2): 179-196.

Feldman, M. S. \& Pentland, B. T. 2003. Reconceptualizing organizational routines as a source of flexibility and change. Administrative Science Quarterly, 48(1):.94-118. 
Felin, T., Foss, N. J. \& Ployhart, R. E. 2015. The microfoundations movement in strategy and organization theory. The Academy of Management Annals, 9(1): 575-632.

Felin, T., Foss, N. J., Heimeriks, K. H. \& Madsen, T. L. 2012. Microfoundations of routines and capabilities: Individuals, processes, and structure. Journal of Management Studies, 49(8): 1351-1374.

Foucault, M. 1977. Discipline and punish. Transl. A. Sheridan. London: Allen Lane.

Frey, B. \& Jegen, R. 2001. Motivation crowding theory. Journal of Economic Surveys, 15(1): 589-611.

Friedland, R. 2017. The value of institutional logics. In G. Krücken, C. Mazza, R. Meyer \& P. Walgenbach (Eds.). New themes in institutional analysis: Topics and issues from European Research: 12-50. Cheltenham, UK: Edward Elgar.

Friedland, R. \& Alford, R. 1991. Bringing society back in: symbols, practices and contradictions. In W. W. Powell \& P.J. DiMaggio (Eds.), The new institutionalism in organizational analysis: 232-263. Chicago: University of Chicago Press.

Garfinkel, H. 1967. “Good” organizational reasons for "bad” clinical records. In H. Garfinkel (Ed), Studies in ethnomethodology: 186-207. Englewood Cliffs, NJ: Prentice-Hall.

Gawande, A. 2010. The checklist manifesto: How to get things right. London: Profile Books.

Gilad, S. 2011. Institutionalizing fairness in financial markets: Mission impossible?. Regulation \& Governance, 5(3): 309-332.

Gond, J.-P., Cabantous, L., Harding, N. \& Learmonth, M. 2016. What do we mean by performativity in organizational and management theory? The uses and abuses of performativity. International Journal of Management Reviews, 18(4): 440-464 
Gray, G. \& Silbey, S. 2014. Governing inside the organization: interpreting regulation and compliance. American Journal of Sociology, 120(1):96-145.

Greenwood, R. \& Hinings, C.R., 1996. Understanding radical organizational change: Bringing together the old and the new institutionalism. Academy of Management Review, 21(4): 1022-1054.

Greenwood, R., Raynard, M., Kodeih, F., Micelotta, E. R. \& Lounsbury M. 2011. Institutional complexity and organizational responses. The Academy of Management Annals, 5:317-71.

Hacking, I. 2002. Making up people. In I. Hacking (Ed.) Historical ontology: 99-114. Cambridge, Ma.: Harvard

Haack, P. \& Schoeneborn, D. 2015. Is decoupling becoming decoupled from institutional theory? A commentary on Wijen. Academy of Management Review, 40(2): 307-310.

Harmon, D., Haack, P. \& Roulet, T. In Press. Microfoundations of institutions: A matter of structure vs. agency or levels of analysis? Academy of Management Review.

Hines, R. D. 1988. Financial accounting: In communicating reality, we construct reality. Accounting, Organizations and Society, 13(3): 251-261.

Hinings, C. R., Logue, D. \& Zietsma, C. 2017. Fields, institutional infrastructure and governance. In R. Greenwood, C. Oliver, T. Lawrence \& R. Meyer (Eds.), The Sage handbook of organizational institutionalism: 216-245. Thousand Oaks, Ca.: Sage. Hirsch, P. M. \& Lounsbury, M. 1997. Ending the family quarrel: Toward a reconciliation of “old" and "new" institutionalisms. American Behavioral Scientist, 40(4): 406-418.

Hood, C. 1995. The "New Public Management" in the 1980s: variations on a theme. 
Hood, C., James, O., Jones, G., Scott, C. \& Travers, T. 1998. Regulation inside government: where new public management meets the audit explosion. Public Money and Management, 18(2): 61-68.

Hopwood, A. G., 1992. Accounting calculation and the shifting sphere of the economic. European Accounting Review, 1(1): 125-143.

Horkheimer, M. \& Adorno, T. W. 2002. G. Noerr (ed.) Transl E. Jephcott. Dialectic of enlightenment. Stanford University Press.

Hull, M. S. 2012. Documents and bureaucracy. Annual Review of Anthropology, 41:.251267.

Jeacle, I. \& Carter, C. 2011. In TripAdvisor we trust: Rankings, calculative regimes and abstract systems. Accounting, Organizations and Society, 36(4): 293-309.

Jepperson, R. 1991. Institutions, institutional effects, and institutionalism. In W.W. Powell \& P.J. DiMaggio (Eds.), The new institutionalism in organizational analysis: 143-163. University of Chicago Press.

Kalev, A., Dobbin, F. \& Kelly, E. 2006. Best practices or best guesses? Assessing the efficacy of corporate affirmative action and diversity policies. American Sociological Review, 71(4): 589-617.

Kaghan, W. \& Lounsbury, M. 2006. Artifacts, articulation work and institutional residue. In A Rafaeli \& M. Pratt (Eds.), Artifacts and organizations: beyond mere symbolism: 259-278. Mahwah, NJ: Lawrence Erlbaum Associates.

Kelly, E. \& Dobbin, F. 1998. How affirmative action became diversity management: Employer response to antidiscrimination law, 1961 to 1996. American Behavioral Scientist, 41(7): 960-984. 
Ketokivi, M., Mantere, S. \& Cornelissen, J. 2017. Reasoning by analogy and the progress of theory. Academy of Management Review, 42(4): 637-658.

Klamer, A. \& McCloskey, D. 1992. Accounting as the master metaphor of economics. European Accounting Review, 1(1): 145-160.

Kraatz, M. S. 2009. Leadership as institutional work: A bridge to the other side. In T. Lawrence, R. Suddaby \& B. Leca (Eds.), Institutional work: Actors and agency in institutional studies of organizations: 59-91. Cambridge, UK: Cambridge University Press. Kraatz, M. S. \& Block, E. S., 2008. Organizational implications of institutional pluralism. In R. Greenwood, C. Oliver, R. Suddaby \& K. Sahlin-Andersson (Eds.), The Sage handbook of organizational institutionalism: 243-275. London: Sage.

Kraatz, M. S. \& Flores, R. 2015. Reinfusing values. In M. Kraatz (Ed.), Institutions and ideals: Philip Selznick's legacy for organizational studies: 353-381. Emerald Group Publishing Limited.

Kraatz, M., Ventresca, M. \& Deng, L. 2010. Precarious values and mundane innovations: Enrollment management in American liberal arts colleges. Academy of Management Journal, 53(6):1521-1545.

Kurunmäki, L. \& Miller, P. 2013. Calculating failure: The making of a calculative infrastructure for forgiving and forecasting failure. Business History, 55(7):1100-1118. Lampel, J. \& Meyer, A.D. 2008. Guest editors' introduction: Field-configuring events as structuring mechanisms: How conferences, ceremonies, and trade shows constitute new technologies, industries, and markets. Journal of Management Studies, 45(6): 1025-1035. Lampland, M. 2010. False numbers as formalizing practices. Social Studies of Science, 40(3): 377-404. 
Langley, A., 1999. Strategies for theorizing from process data. Academy of Management Review, 24(4): 691-710.

Lawrence, T., Suddaby, R. \& Leca, B. (Eds.). 2009. Institutional work: actors and agency in institutional studies of organizations. Cambridge: Cambridge University Press.

Lewis, S. \& Boyle, M. 2017. The expanding role of traceability in seafood: tools and key initiatives. Journal of Food Science, 82(S1): A14-A21

Lezaun, J. 2006. Creating a new object of government: making genetically modified organisms traceable. Social Studies of Science, 36(4): 499-531.

Lok, J., Creed, W. E. D., DeJordy, R. \& Voronov, M., 2017. Living institutions: Bringing emotions into organizational institutionalism. In R. Greenwood, C. Oliver, T. Lawrence \& R. Meyer (Eds.), The Sage handbook of organizational institutionalism: 691-620. Thousand Oaks, Ca.: Sage.

Lounsbury, M. 2008. Institutional rationality and practice variation: new directions in the institutional analysis of practice. Accounting, Organizations and Society, 33(4-5):349-361.

Lupton, D. 2016. The diverse domains of quantified selves: self-tracking modes and dataveillance. Economy and Society, 45(1): 101-122.

MacKenzie, D. 2006. An engine, not a camera: How financial models shape markets. Cambridge, Ma.: MIT Press.

MacKenzie, D., Muniesa, F. \& Siu, L. 2007. Introduction. In D. MacKenzie, F. Muniesa \& L. Siu (Eds.), Do economists make markets? On the performativity of economics: 1-19. Princeton University Press, Princeton.

Marquis, C. \& Tilcsik, A. 2013. Imprinting: Toward a multilevel theory. Academy of Management Annals, 7(1): 195-245. 
Marquis, C., Toffel, M. W. \& Zhou, Y., 2016. Scrutiny, norms, and selective disclosure: A global study of greenwashing. Organization Science, 27(2): 483-504.

Marti, W. \& Gond, J-P. 2018. Why do theories become self-fulfilling? Exploring the boundary conditions of performativity. Academy of Management Review, 43(3): 487-508.

Mazmanian, M. \& Beckman, C. M. 2018. “Making” your numbers: Engendering organizational control through a ritual of quantification. Organization Science, 29(3): 357379.

McGivern, G.\& Ferlie, E. 2007. Playing tick-box games: Interrelating defences in professional appraisal. Human Relations, 60(9):.1361-1385.

McPherson, C. M. \& Sauder, M. 2013. Logics in action: Managing institutional complexity in a drug court. Administrative Science Quarterly, 58(2): 165-196.

Mennicken, A. M.\& Espeland, W. In press. What's new with numbers? Sociological approaches to the study of quantification. Annual Review of Sociology.

Merconi, R. 2003. On auditing audit trail. Security Watch, 46 (1):17-20.

Meyer, J.W. 1986. Social environments and organizational accounting. Accounting, Organizations and Society, 11(4-5): 345-356.

Meyer, J. W. \& Rowan, B. 1977. Institutionalized organizations: Formal structure as myth and ceremony. American Journal of Sociology, 83(2): 340-363.

Miller, P., 1992. Accounting and objectivity: the invention of calculating selves and calculable spaces. Annals of Scholarship, 9(1/2): 61-86.

Miller, P. \& O'Leary, T. 1987. Accounting and the construction of the governable person. Accounting, Organizations and Society, 12: 235-65. 
Miller, P. \& Power, M. 2013. Accounting, organizing and economizing: connecting accounting research and organization theory. The Academy of Management Annals, 7(1):557-605.

Miller, P. \& Rose, N. 1990. Governing economic life. Economy and Society, 19(1): 1-31.

Munro, E. 2004. The impact of audit on social work practice. British Journal of Social Work, 34(8):.1075-1095.

Mutch, A. 2018. Practice, substance and history: reframing institutional logics. Academy of Management Review, 43(2): 242-258.

Oliver, C., 1991. Strategic responses to institutional processes. Academy of Management Review, 16(1): 145-179.

Orlikowski, W. \& Scott, S. 2014. What happens when evaluation goes online? Exploring apparatuses of valuation in the travel sector. Organization Science, 25(3):868-91.

Pache, A. C. \& Santos, F. 2010. When worlds collide: The internal dynamics of organizational responses to conflicting institutional demands. Academy of Management Review, 35(3): 455-476.

Pache, A. C. \& Santos, F. 2013. Inside the hybrid organization: Selective coupling as a response to competing institutional logics. Academy of Management Journal, 56(4): 972 1001.

Palermo, T., Power, M. \& Ashby, S. 2017. Navigating institutional complexity: the production of risk culture in the financial sector. Journal of Management Studies, 54(2): 154-181.

Pentland, B.T. 1993. Getting comfortable with the numbers: Auditing and the microproduction of macro-order. Accounting, Organizations and Society, 18(7-8): 605-620. 
Pentland, B., Haerem, T. \& Hillison, D. 2011. The (N)ever-changing world: stability and change in organizational routines. Organization Science, 22:1369-83

Pflueger, D. 2016. Knowing patients: The customer survey and the changing margins of accounting in healthcare. Accounting, Organizations and Society, 53:.17-33.

Phillips, N., Lawrence, T. B. \& Hardy, C. 2004. Discourse and institutions. Academy of Management Review, 29(4): 635-652.

Powell, W. \& Rerup. 2017. Opening the black box: the microfoundations of institutions. In R. Greenwood, C. Oliver, T. Lawrence \& R. Meyer (Eds.). The Sage handbook of organizational institutionalism, 387-416. Thousand Oaks, Ca.: Sage.

Power, M. 1996. Making things auditable. Accounting, Organizations and Society, 21 (2/3): 289-315.

Power, M. 1997. The audit society: rituals of verification. Oxford: Oxford University Press.

Power, M. 2015. How accounting begins: Object formation and the accretion of infrastructure. Accounting, Organizations and Society, 47: 43-55.

Power, M. 2016. Postscript: On riskwork and auditwork. In M. Power (Ed.), Riskwork: essays on the organizational life of risk management: 274-284. Oxford: Oxford University Press.

Power, M. In press. Infrastructures of traceability. In M. Kornberger, G. Bowker, N. Pollock, P. Miller, A. Mennicken, J. Randa Nucho \& J. Elyachar (Eds.), Thinking infrastructures: Research in the sociology of organizations. Bingley UK: Emerald Group Publishing Limited. 
Quattrone, P. 2015. Governing social orders, unfolding rationality, and Jesuit accounting practices: a procedural approach to institutional logics. Administrative Science Quarterly, $60(3), 411-445$.

Riles, A. 2006. (Ed.). Documents: artifacts of modern knowledge. University of Michigan Press.

Rival, A., Montet, D. \& Pioch, D. 2016. Certification, labelling and traceability of palm oil: can we build confidence from trustworthy standards? $\boldsymbol{O C L}, 23(6)$ : D609.

Roberts, J. 2018. Managing only with transparency: The strategic functions of ignorance. Critical Perspectives on Accounting, 55: 53-60.

Sauder, M. \& Espeland, W. N. 2009. The discipline of rankings: Tight coupling and organizational change. American Sociological Review, 74(1): 63-82.

SEC. 2005. Roundtable discussion on implementation of internal control reporting provisions. Washington DC: United States Securities and Exchange Commission.

Selznick, P. 1957. Leadership in administration: A sociological interpretation. Berkeley, Ca.: University of California Press.

Selznick, P. 1996. Institutionalism "old" and" new". Administrative Science Quarterly, 41(2): 270-277.

Sharon, T. \& Zandbergen, D. 2017. From data fetishism to quantifying selves: Self-tracking practices and the other values of data. New Media \& Society, 19(11): 1695-1709.

Shore, C. \& Wright, S. 2015. Audit culture revisited: Rankings, ratings, and the reassembling of society. Current Anthropology, 56(3): 431-432. 
Sitkin, S. \& Bies, R. 1994. The legalization of organizations: a multi-theoretical perspective. In S. Sitkin \& R. Bies (Eds.), The legalistic organization:19-49. Thousand Oaks, Ca: Sage. Smith, D. 1984. Textually mediated social organization. International Social Science Journal, 36:59-75

Strang, D. \& Meyer, J. W. 1993. Institutional conditions for diffusion. Theory and Society, 22(4): 487-511.

Strathern, M., 1997. "Improving ratings": audit in the British University system. European Review, 5(3): 305-321.

Strathern, M. (Ed.). 2000a. Audit cultures: anthropological studies in accountability, ethics and the academy. London: Routledge.

Strathern, M. 2000b. The tyranny of transparency. British Educational Research Journal, 26(3): 309-321.

Suddaby, R., Cooper, D. J. \& Greenwood, R., 2007. Transnational regulation of professional services: Governance dynamics of field level organizational change. Accounting, Organizations and Society, 32(4-5): 333-362.

Swedberg, R. 2014. From theory to theorizing. In R. Swedberg (Ed.). Theorizing in social science: the context of discovery: 1-28. Stanford, CA.: Stanford University Press.

Thornton, P. H., Jones, C. \& Kury, K., 2005. Institutional logics and institutional change in organizations: Transformation in accounting, architecture, and publishing. In C. Jones \& P. H. Thornton (Eds.), Transformation in cultural industries (Research in the sociology of organizations), 23:125-170. Emerald Group Publishing Limited.

Thornton, P. H., Ocasio, W. \& Lounsbury, M. 2012. The institutional logics perspective: A new approach to culture, structure, and process. Oxford University Press. 
Townley, B. 1993. Foucault, power/knowledge, and its relevance for human resource management. Academy of Management Review, 18(3): 518-545.

Townley, B. 1997. The institutional logic of performance appraisal. Organization Studies, 18(2): 261-285.

Tsoukas, H., 1997. The tyranny of light: The temptations and the paradoxes of the information society. Futures, 29(9): 827-843.

Turner, S. F. \& Cacciatori, E., 2016. The multiplicity of habit. Implications for routines research. In J. Howard-Grenville, C. Rerup, A. Langley \& H. Tsoukas (Eds), Organizational routines: How they are created, maintained, and changed: 71- 95. Oxford University Press. Vaara, E. \& Whittington, R. 2012. Strategy-as-practice: Taking social practices seriously. Academy of Management Annals, 6(1): 285-336.

Van Maanen, J. \& Pentland, B. 1994. Cops and auditors: the rhetoric of records. In S. Sitkin and R. Bies (Eds.) The legalistic organization, 53-90. Thousand Oaks, Ca: Sage.

Vollmer H, Mennicken A \& Preda A. 2009. Tracking the numbers: Across accounting and finance, organizations and markets. Accounting, Organizations and Society. 34(5): 619-37.

Voronov, M. \& Weber, K. 2016. The heart of institutions: Emotional competence and institutional actorhood. Academy of Management Review, 41(3): 456-478.

Wijen, F. 2014. Means versus ends in opaque institutional fields; trading off compliance and achievement in sustainability standard adoption. Academy of Management Review, 39(3):302-323n.

Wijen, F. 2015. Coupling, not decoupling, should be institutional theory's mantra: A rejoinder to Haack and Schoeneborn. Academy of Management Review, 40(2): 310-313. 
Winter, S.G. 2013. Habit, deliberation, and action: Strengthening the microfoundations of routines and capabilities. The Academy of Management Perspectives, 27(2): 120-137.

Wittgenstein, L. 1976 [1953] Translated by G.E. Anscombe. Philosophical investigations. Oxford: Blackwell

WWF. 2015. Traceability principles for wild-caught fish products.

https://www.worldwildlife.org/publications/traceability-principles-for-wild-caught-fishproducts Accessed 2018 January $9^{\text {th }}$

Zajac, E. J. \& Westphal, J.D. 2004. The social construction of market value: Institutionalization and learning perspectives on stock market reactions. American Sociological Review, 69(3): 433-457.

Zucker, L. G. 1977. The role of institutionalization in cultural persistence. American Sociological Review, 726-743.

Zuckerman, E. W. 2010. What if we had been in charge? The sociologist as builder of rational institutions. In M. Lounsbury \& P. Hirsch (Eds.), Markets on trial: The economic sociology of the US financial crisis (Research in the sociology of organizations), 30B: 359378. Emerald Group Publishing Limited. 
TABLE 1

Performativity and the audit trail process

\begin{tabular}{|l|l|l|l|l|}
\hline Time & $\begin{array}{l}\text { Form of performativity } \\
\text { (based on MacKenzie, 2006 } \\
\text { typology) }\end{array}$ & $\begin{array}{l}\text { A: Production of } \\
\text { primary traces } \\
\text { (externalization) }\end{array}$ & $\begin{array}{l}\text { B: Emergence of } \\
\text { performance facticity in } \\
\text { performance accounts } \\
\text { (objectification) }\end{array}$ & $\begin{array}{l}\text { C: Formation of disposition } \\
\text { (to reproduce audit trails) } \\
\text { (internalization) }\end{array}$ \\
\hline T1 & $\begin{array}{l}\text { Weak = "Generic" (Accounting is } \\
\text { simply adopted and produced by } \\
\text { organizational actors) }\end{array}$ & Compliant adoption & $\begin{array}{l}\text { Weak Pull } \\
\text { (conventional) }\end{array}$ & $\begin{array}{l}\text { Weak } \\
\text { (critical-reflexive push) }\end{array}$ \\
\hline T2 & $\begin{array}{l}\text { Medium = "Effective" } \\
\text { (Accounting has effects on } \\
\text { organizational processes) }\end{array}$ & Routinization & $\begin{array}{l}\text { Medium Pull } \\
\text { (becoming naturalised) }\end{array}$ & $\begin{array}{l}\text { Medium } \\
\text { (strategic-reflexive) }\end{array}$ \\
\hline & $\begin{array}{l}\text { Strong = "Barnesian" (Accounting } \\
\text { production makes organizational } \\
\text { processes and actors more like } \\
\text { their accounting representations) }\end{array}$ & Amplification & $\begin{array}{l}\text { Strong Pull } \\
\text { (fully naturalised) }\end{array}$ & $\begin{array}{l}\text { Strong } \\
\text { (habitual- pre-reflexive) }\end{array}$ \\
\hline
\end{tabular}


Figure 1

The Performative Logic of the Audit Trail
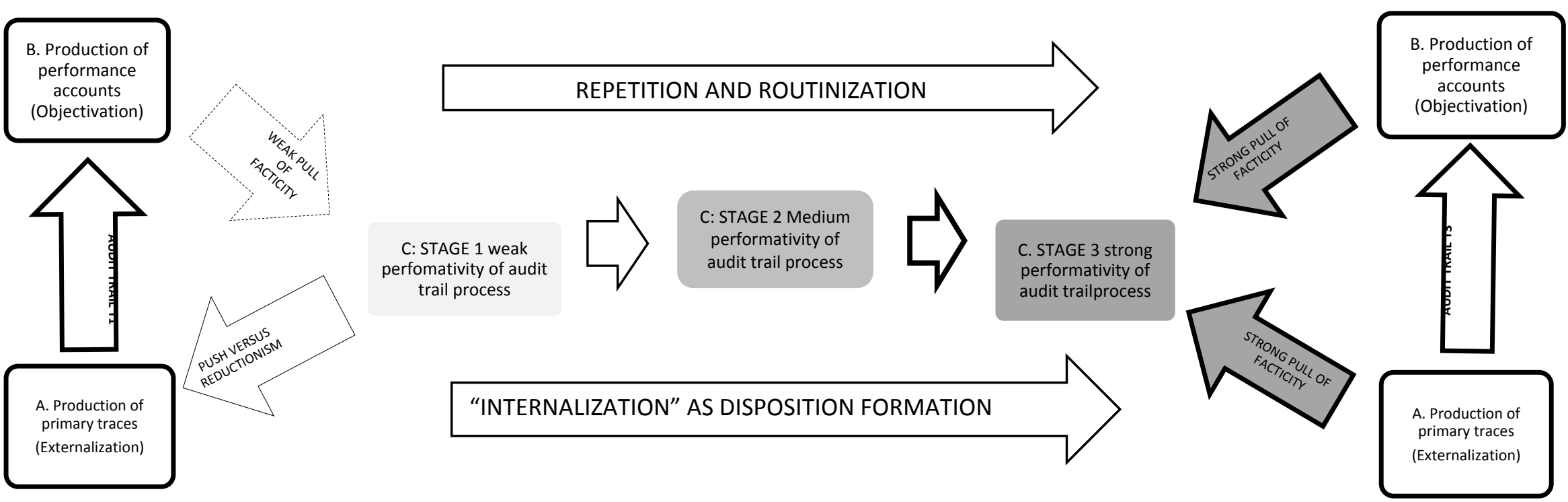
Michael Power (m.k.power@lse.ac.uk) is professor of accounting at the London School of Economics and a Fellow of the British Academy. He obtained a PhD in philosophy from Cambridge UK. His research and teaching focus on regulation, accounting, auditing, risk management, internal control and organization theory. 